PROF. MAURIZIO MENCUCCINI (Orcid ID : 0000-0003-0840-1477)

MISS TERESA ROSAS (Orcid ID : 0000-0002-8734-9752)

DR BRENDAN CHOAT (Orcid ID : 0000-0002-9105-640X)

PROF. ÜLO NIINEMETS (Orcid ID : 0000-0002-3078-2192)

DR JORDI MARTÍNEZ-VILALTA (Orcid ID : 0000-0002-2332-7298)

Article type :- Regular Manuscript

\title{
Leaf economics and plant hydraulics drive leaf : wood area ratios
}

Maurizio Mencuccini ${ }^{1,2^{*}}$, Teresa Rosas ${ }^{1,3}$, Lucy Rowland ${ }^{4}$, Brendan Choat ${ }^{5}$, Hans Cornelissen ${ }^{6}$, Steven Jansen ${ }^{7}$, Koen Kramer $^{8}$, Andrei Lapenis ${ }^{9}$, Stefano Manzoni ${ }^{10,11}$, Ülo Niinemets ${ }^{12,13}$, Peter Reich ${ }^{5,14}$, Franziska Schrodt ${ }^{15}$, Nadia Soudzilovskaia ${ }^{16}$, Ian H Wright ${ }^{17}$, Jordi MartínezVilalta ${ }^{1,3}$

${ }^{1}$ CREAF, E08193 Bellaterra, Barcelona, Spain

${ }^{2}$ ICREA, Pg. Lluís Companys 23, 08010 Barcelona (Spain).

${ }^{3}$ Universitat Autònoma de Barcelona, E08193 Bellaterra, Barcelona, Spain

${ }^{4}$ Department of Geography, College of Life and Environmental Sciences, University of Exeter, EX4 4QE Exeter, UK

${ }^{5}$ Hawkesbury Institute for the Environment, Western Sydney University, Locked Bag 1797

Penrith 2751 NSW, Australia

This article has been accepted for publication and undergone full peer review but has not been through the copyediting, typesetting, pagination and proofreading process, which may lead to differences between this version and the Version of Record. Please cite this article as doi: 10.1111/nph.15998

This article is protected by copyright. All rights reserved. 
${ }^{6}$ Systems Ecology, Department of Ecological Science, Vrije Universiteit, De Boelelaan 1081, 1081 HV Amsterdam, The Netherlands

${ }^{7}$ Ulm University, Institute of Systematic Botany and Ecology, Albert-Einstein-Allee 11, 89081

Ulm, Germany

${ }^{8}$ Wageningen University and Research, Droevendaalsesteeg 1, 6700 AA, Wageningen, The Netherlands

${ }^{9}$ Department of Geography, New York State University at Albany, 12222 Albany, NY, USA

${ }^{10}$ Physical Geography, Stockholm University, SE-10691 Stockholm, Sweden

${ }^{11}$ Bolin Centre for Climate Research, Stockholm University, SE-10691 Stockholm, Sweden

${ }^{12}$ Estonian University of Life Science, Kreutzwladi 1, 51006 Tartu, Estonia

${ }^{13}$ Estonian Academy of Sciences, Kohtu 6, 10130 Tallinn, Estonia

${ }^{14}$ Department of Forest Resources, University of Minnesota, St. Paul, MN 55108 USA

${ }^{15}$ School of Geography, University of Nottingham, NG7 2RD Nottingham, UK

${ }^{16}$ Institute of Environmental Sciences, CML, Leiden University; Einsteinweg 2, 2333 CC Leiden, The Netherlands

${ }^{17}$ Department of Biological Sciences, Macquarie University, Sydney NSW 2109, Australia

*corresponding author.

Maurizio Mencuccini

CREAF, Universidad Autonoma de Barcelona

Cerdanyola del Valles 08193

(Barcelona, Spain)

m.mencuccini@creaf.uab.cat

tel. +34-93-5868474

Received: 21 May 2019

Accepted: 8 June 2019

This article is protected by copyright. All rights reserved. 


\section{Contributions by authors:}

$M M, T R, J M-V$ and $B C$ conceived and implemented the research; MM analyzed the data with $\mathrm{JM}-\mathrm{V}, \mathrm{BC}$ and TR; MM wrote the first draft with contributions from TR, JM-V, IHW; all coauthors (MM, TR, LR, BC, HC, SJ, KK, AL, SM, ÜN, PR, FS, NS, IHW, JM-V) contributed to data collection and revisions.

Keywords: Huber value, xylem hydraulics, leaf economics spectrum, wood density, leaf size, Corner's rules, biomechanics, trait tradeoff

\section{Orcid codes:}

Maurizio Mencuccini, http://orcid.org/0000-0003-0840-1477.

Teresa Rosas, https://orcid.org/0000-0002-8734-9752.

Lucy Rowland, https://orcid.org/0000-0002-0774-3216.

Brendan Choat

Hans Cornelissen, https://orcid.org/0000-0002-2346-1585.

Steven Jansen

Koen Kramer, https://orcid.org/0000-0002-1402-2775.

Andrei Lapenis, https://orcid.org/0000-0002-2135-3636.

Stefano Manzoni, https://orcid.org/0000-0002-5960-5712.

Ülo Niinemets, https://orcid.org/0000-0002-3078-2192.

Peter Reich, http://orcid.org/0000-0003-4424-662X.

Franziska Schrodt, https://orcid.org/0000-0001-9053-8872.

Nadia Soudzilovskaia

Ian H Wright, https://orcid.org/0000-0001-8338-9143.

Jordi Martínez-Vilalta: https://orcid.org/0000-0002-2332-7298.

This article is protected by copyright. All rights reserved. 


\section{Abstract}

Biomass and area ratios between leaves, stems and roots regulate many physiological and ecological processes. The Huber value $H_{v}$ (sapwood area/leaf area ratio) is central to plant water balance and drought responses. However, its coordination with key plant functional traits is poorly understood, which prevents developing trait-based prediction models.

Based on theoretical arguments, we hypothesise that global patterns in $H_{v}$ of terminal woody branches can be predicted from variables related to plant trait spectra, i.e., plant hydraulics and size and leaf economics.

Using a global compilation of 1135 species-averaged $H_{v}$, we show that $H_{v}$ varies over 3 orders of magnitude. Higher $H_{v}$ are seen in short small-leaved low-SLA shrubs with low $K_{\mathrm{s}}$ in arid relative to tall large-leaved high-SLA trees with high $K_{\mathrm{s}}$ in moist environments. All traits depend on climate but climatic correlations are stronger for explanatory traits than $H_{v}$. Negative isometry is found between $H_{v}$ and $K_{\mathrm{s}}$, suggesting a compensation to maintain hydraulic supply to leaves across species.

This work identifies the major global drivers of branch sapwood/leaf area ratios. Our approach based on widely available traits facilitates the development of accurate models of aboveground biomass allocation and helps predict vegetation responses to drought.

\section{Introduction}

Plant growth and survival depend in large part on the traits of individual plant organs and on the partitioning of resources to these organs (Thornley 1972; Grime 1979; Tilman 1988; Westoby 1998). Hence, biomass partitioning integrates key physiological and ecological processes (Hunt \& Cornelissen 1997; Shipley 2006; Poorter et al. 2015). At the global scale, the biomass ratios between leaves, stems and roots are known to be affected by abiotic factors such as temperature (Gill \& Jackson, 2000; Lapenis et al., 2005; Reich et al., 2014a; Reich et al., 2014b; Freschet et al., 2017), light (Poorter et al. 2012, 2019), potential evapotranspiration (Ledo et al. 2017), soil water stress (Lapenis et al., 2005; Poorter et al., 2012) and nutrients (Poorter et al. 2012; Freschet et al. 2017), and biotic factors such as plant size (Poorter et al. 2015; Ledo et al. 2017). Biomass ratios globally have also been reported to vary among plant functional types, e.g., eudicots invest more in leaf tissues than monocots and gymnosperms more than angiosperms (Poorter et al. 2012; Duursma \& Falster 2016). While global patterns in biomass ratios are beginning to be elucidated, how specific traits affect the partitioning among plant tissues is not well understood.

Functional balance and adaptive dynamics theories (Thornley 1972; Bloom et al. 1985; Franklin et al. 2012; Farrior et al. 2013) suggest that, over evolutionary time scales, partitioning should be regulated to guarantee access to the most limiting resource in competitive and variable

This article is protected by copyright. All rights reserved. 
environments. However, complications arise because plant size declines with reduced resource availability (Coleman et al. 1994; McCarthy \& Enquist 2007), biomass partitioning varies with plant size (Enquist \& Niklas 2002; Poorter et al. 2015), and because biomass ratios reflect both partitioning and turnover times (Thornley 1972; Gill \& Jackson 2000; Reich 2002; Niinemets 2010). Additionally, hydraulic (Tyree \& Ewers 1991) and biomechanical (Niklas \& Spatz 2010) properties of stems depend on stem cross-sectional areas and their geometry, rather than their mass. Similarly, leaf gas exchange occurs via the leaf surface. Thus, in order to predict tissue partitioning, relationships between leaf and xylem cross-section areas should be considered in addition to mass ratios; indeed, links to water relations and plant hydraulics can only be understood this way.

To develop predictions of the area ratios between stem and leaves, we employ here the Huber value (xylem sapwood area / leaf area, $H_{v}$ ) of crown-top branches (Tyree \& Ewers 1991). The $H_{v}$ can be viewed as the ratio of investment in xylem area (i.e., excluding pith, heartwood, stem bark and phloem) over the expected gains obtained by leaf display and thus, it is an essential parameter in models of water use by vegetation (Mencuccini et al. 2019). It is employed to convert xylem-area specific conductivity $K_{\mathrm{s}}$ into a more physiologically meaningful variable, i.e., leaf-area specific conductivity $K_{\mathrm{L}}\left(K_{\mathrm{L}}=K_{\mathrm{S}} H_{\mathrm{v}}\right)$, thereby linking the unit-area water flux through plants with the water potential gradient necessary to drive that flux. To facilitate understanding and prediction of $H_{v}$, we explore here the idea that $H_{v}$ may be constrained by the functional properties of leaves and xylem, which in turn are dependent on climate and resource availability.

The need to build sufficient xylem hydraulic capacity to supply the canopy, given a certain distance between roots and leaves (Zimmermann 1983; Tyree \& Ewers 1991), provides a first constraint; i.e., higher $K_{\mathrm{s}}$ may be required for thin and long stems to compensate pressure losses along a longer hydraulic pathway. A second trade-off comes from Corner's rules (Corner 1949). Corner's rules state that larger individual leaves are generally subtended by thicker stems and are more widely spaced in branches. While the second rule describes an axis of plant architectural variation, Corner's first rule relates to leaf packing, implying that for a given leaf area, the trade-offs between building many small leaves or few large ones have consequences for stem size (Westoby \& Wright 2003; Kleiman \& Aarssen 2007; Olson et al. 2009; Smith et al. 2017). A third trade-off relates to the partitioning towards leaf area construction in relation to the carbon returned by photosynthesis (Kikuzawa 1991; Reich et al. 1997; Wright et al. 2004; Shipley et al. 2006). The central trait mediating this trade-off is $S L A$, which is the ratio between radiation-intercepting leaf area and required mass investment (Niinemets 1999, 2001). Finally, wood density (WD) might control the amount of biomass investment in xylem cross-sectional areas. High WD increases

This article is protected by copyright. All rights reserved. 
mechanical stiffness, resistance to breakage (Niklas \& Spatz 2006; Chave et al. 2009) and cavitation (Hacke et al. 2001), but results in high carbon costs, especially for tall trees (Mencuccini 2003). Hence, the trade-offs between building thin terminal branches with dense wood or building thick branches with low density (Niklas \& Spatz 2010) may have consequences for the ratios between xylem and leaf areas. Although some of the relationships highlighted above are employed in other plant leaf-seed-size spectra (e.g., Westoby 1998; Díaz et al. 2016; Hodgson et al. 2017; Pierce et al. 2017), the focus on hydraulic traits makes this global analysis distinctive. While Corner's rules do not distinguish between the components of branch cross-sectional area, $H_{v}$ only considers tissues potentially involved in water transport. Additionally, because $H_{v}$ is defined based on activelyconducting sapwood, turnover times of sapwood into heartwood are implicitly considered. Finally, although the $H_{v}$ dataset reported here refers to samples of crown-top terminal branches only, variations in $H_{v}$ within a plant canopy are relatively constrained (cf., review in Mencuccini et al. 2019).

Based on the considerations above, we develop a trait-based predictive model for $H_{\mathrm{v}}$. As a starting point, we employ the definition of $H_{v}\left(\mathrm{~cm}^{2} \mathrm{~m}^{-2}\right)$ to partition the identity into component variables:

$$
H_{v}=\frac{A_{x}}{A_{L, t o t}}=\frac{A_{x}}{\sum A_{L}}=\frac{A_{x}}{S L A n M_{L}}
$$

where $A_{x}$ and $A_{L, \text { tot }}$ are xylem sapwood area $\left(\mathrm{cm}^{2}\right)$ and subtended leaf area $\left(\mathrm{m}^{2}\right)$, respectively. The capital sigma in the denominator indicates a summation over all leaves of a crown-top twig; $A_{L}$, $M_{L}$ and $S L A$ are mean area of a leaf $\left(\mathrm{m}^{2}\right)$, mean mass of a leaf $(\mathrm{kg})$ and mean specific leaf area $\left(\mathrm{m}^{2} \mathrm{~kg}^{-}\right.$ ${ }^{1}$ ), respectively; $n$ is the number of leaves in a branch of a given length. SLA is known to depend on light availability within tree crowns (e.g., Niinemets et al. 2015), while $H_{v}$ reflects only conditions of canopy-top branches. Eqn. 1 predicts a negative scaling for $H_{v}$ against both $M_{L}$ and $S L A$, equivalent to slopes of -1 once variables are log-transformed. In practice, negative isometric scaling $(b=-1.00)$ is not expected between these variables, because of, among other factors, non-zero covariances between $M_{\mathrm{L}}$ and $S L A$ and between $M_{\mathrm{L}}$ and $n$. SLA and $M_{\mathrm{L}}$ act very distinctively with regard to how they might affect $H_{\mathrm{v}}$. Doubling SLA halves $H_{\mathrm{v}}$ without changes in leaf biomass. Conversely, doubling $M_{\llcorner}$halves $H_{v}$ by doubling leaf biomass. The presence of $A_{x}$ in the numerator of Eqn. 1 suggest a sizedependency. To incorporate it, the potential hydraulic conductance of a plant can be expressed as $K_{\mathrm{p}}$ $=K_{\mathrm{s}} A_{\mathrm{x}} / H_{\max }$, where $K_{\mathrm{p}}\left(\mathrm{kg} \mathrm{MPa}^{-1} \mathrm{~s}^{-1}\right), K_{\mathrm{s}}\left(\mathrm{kg} \mathrm{m}^{-1} \mathrm{MPa}^{-1} \mathrm{~s}^{-1}\right)$ and $H_{\max }(\mathrm{m})$ are potential plant hydraulic conductance, branch specific conductivity and plant maximum height (strongly related to maximum hydraulic path length), respectively. Conductance $K_{\mathrm{p}}$ is referred to as 'potential' because it does not

This article is protected by copyright. All rights reserved. 
account for actual path length, only maximum height, and neglects reductions of water flow due to cavitation. We employ $H_{\max }$ instead of actual plant height, because sampling heights are not available for the majority of our samples. Hence our results must be understood with regard to the effects of plant potential stature (i.e., maximum height), not actual height per se, on these relationships. We recognise that metabolic scaling theory (MST, West et al. 1999; Savage et al. 2010) provides suitable expressions for scaling against plant height. We do not employ quarter-power relationships, as our intention is not to test our global dataset against predictions from MST, but to explore the joint covariation of leaf economics, xylem and plant traits in relation to $H_{v}$. Substituting $K_{\mathrm{p}} H_{\max } / K_{\mathrm{s}}$ for $A_{\mathrm{x}}$ into Eqn.1 gives:

$$
H_{v}=\frac{K_{p}}{n} \frac{H_{\max }}{S L A K_{S} M_{L}}
$$

The first term on the right hand side of the equation contains the ratio $K_{\mathrm{p}} / n$, the total stem hydraulic supply capacity to each leaf. Both $K_{p}$ and $n$ are dependent on stem diameter (Mencuccini 2002; Savage et al. 2010; Smith et al. 2017), while $K_{\mathrm{p}} / n$ is much less so (West et al. 1999). The second term on the right hand side of Eqn. 2 predicts a direct scaling of $H_{v}$ with $H_{\max }$ and an inverse scaling with $K_{\mathrm{s}}, S L A$ and $M_{\mathrm{L}}$. The direct scaling of $H_{\mathrm{v}}$ with $H_{\max }$ ensures that taller plants have greater relative allocation to xylem area to compensate for their stature (McDowell et al. 2002). This compensation is moderated by other processes; i.e., vertical conduit tapering (West et al. 1999; Anfodillo et al. 2006) and larger conduits at the apex of tall plants (Olson et al. 2014, 2018), both of which affect $K_{s}$. An inverse scaling of $H_{v}$ with $H_{\max }$ may thus also be obtained, if $K_{\mathrm{s}}$ scaled with $H_{\max }$ more than proportionally. A negative scaling of $H_{v}$ with $H_{\max }$ may also be obtained if tall trees grow relatively less sapwood than shorter plants (for a given leaf area) to minimise sapwood construction and/or maintenance costs, instead of hydraulic resistance (Anfodillo et al. 2016; Fajardo et al. 2019). An inverse relationship between $H_{v}$ and $K_{\mathrm{s}}$ is expected because of functional balance between water supply and demand (Whitehead \& Jarvis, 1981; see derivation in the Supplementary Information, Methods S1) and it has been found empirically before for smaller datasets (Choat et al. 2011; Gleason et al. 2012).

Equations 1-2 express $H_{\mathrm{v}}$ in term of the constituent traits, thus providing a predictive reference framework for tissue partitioning based on organ-specific traits. Following Eqn.2, we test the hypotheses that the relative partitioning between sapwood area and leaf area $\left(H_{v}\right)$ is affected jointly by leaf, xylem and plant traits. Specifically, we test the hypotheses that $H_{v}$ declines with a) SLA and leaf size, b) xylem hydraulic efficiency $K_{\mathrm{s}}$, but c) increases with maximum tree height $H_{\max }$. Additionally, we also test a hypothesis related to wood economics, i.e., that d) $H_{v}$ declines with $W D$

This article is protected by copyright. All rights reserved. 
(strictly, stem specific density). A negative relationship between $H_{v}$ and $W D$ may arise because of xylem carbon construction costs (cf., Supplementary Materials Methods S1 for in-depth discussion). Although WD is not employed in Eqns. 1 and 2, it allows pointing more precisely at additional physiological variables not explored in the analysis and it is a widely available trait. Because biomass ratios are known to vary with abiotic factors, we explore also e) whether this is the result of direct climatic effects on $H_{v}$ as previously proposed (e.g., Mencuccini \& Grace 1995) or whether they only act indirectly on the component traits. Finally, we tested a model excluding $K_{\mathrm{s}}$ from the set of traits employed to predict $H_{v}$. The advantage of excluding $K_{\mathrm{s}}$ is that it allows obtaining a model for $H_{v}$ based only on widely available easy-to-measure traits, making it possible to employ global databases to predict sapwood-leaf area ratios. Overall, our analyses provide the first approximation to a framework explaining the variability in a difficult-to-predict allocation trait, based on standard leaf and xylem traits and plant stature. Understanding how partitioning between leaves and wood in terminal branches is jointly determined by leaf and wood properties is a significant step towards predicting how organ-level traits can affect global patterns of biomass partitioning and vegetation responses to drought.

\section{Materials and Methods}

\section{Datasets}

Measured values of crown-top branch $H_{v}$ were obtained from a) an updated version of the hydraulic dataset by Choat et al. (2012) (i.e., XFT, xylem functional traits), including several new datasets from China, b) an Amazonian dataset from RAINFOR (Patiño et al. 2012), c) an Australian dataset (from Togashi et al. 2015) and d) an African/S. American dataset from TROBIT (Schrodt et al. 2015). Smaller datasets from China were obtained from (Niu et al., 2017; Song et al., 2018). The geographical distribution of sampling sites/species location is given in Fig.S1 and the biome distribution plot in Fig. S2. The RAINFOR and the TROBIT projects (accounting for $\sim 50 \%$ of all $H_{v}$ here) followed a single protocol for the measurement of leaf area, mass, xylem area, SLA and wood density (Patiño 2005). Specifically, 1-m-long top-canopy branches were sampled typically at the end of the rainy season (leaf phenology can be variable and is poorly predictable in the tropics, e.g., $\mathrm{Wu}$ et al., 2016) from sun-exposed crowns of trees of diameter at breast height $>10 \mathrm{~cm}$. Bark, heartwood if present, and xylem pith were visually excluded from xylem measurements. However, since dyes were not routinely used, hydraulically active xylem was not identified. For the hydraulic dataset ( $50 \%$ of the entries), crown top samples were also typically collected. Units and protocols were

This article is protected by copyright. All rights reserved. 
checked by experts, although study-to-study variability in sampling/measurement methods may be present in our sample (especially, regarding use of dyes and sample length). Measurements conducted on seedlings, inside greenhouses and those subjected to experimental treatments were excluded from this study. Values of wood specific conductivity $K_{\mathrm{s}}$ were obtained from the updated XFT, leaf economics traits (SLA, leaf lifespan LL), $H_{\max }$ and WD from XFT and Glopnet (Wright et al. 2004), (Patiño et al. 2012), (Schrodt et al. 2015) and/or TRY (Kattge et al., 2011). Xylem vulnerability to embolism from XFT was employed for one analysis, for which r-shaped curves were excluded. Individual, one-sided projected leaf areas $A_{L}$ were obtained from (Wright et al. 2017) and leaf masses $M_{\mathrm{L}}$ calculated by dividing $A_{\mathrm{L}}$ by $S L A$.

Information on genus-level woodiness, leaf habit, leaf type, leaf shape and plant growth form were obtained from the sources above or from (Zanne et al. 2014). When required, missing pieces of information were extracted by web scraping of wiki pages from Wikipedia (https://en.wikipedia.org/wiki/Main_Page), Encyclopaedia of Life (http://eol.org/), Flora of China (http://www.efloras.org) and Useful Tropical Plants (http://tropical.theferns.info/) using xm/2, rvest and $h t t r$ in R (R Core Team 2017). When a certain species was given different categories of growth form, we followed (Castorena et al. 2015) and classified the plant in the largest category (e.g., if the species was listed as shrub and tree, we classed the species as tree). The dataset was finally trimmed to the following levels for each categorical variable: woodiness (woody only), leaf habit (winter and drought-deciduous, evergreen), leaf shape (compound, simple), leaf type (needle leaf, broadleaf), plant habit (shrub, tree) and taxon group (Angiosperm, Gymnosperm). The final dataset contained 1135 species-averaged $H_{v}$ values from 736 sites (1618 unique values when including lianas, vines, succulents and cacti). The other quantitative variables had somewhat lower coverage (i.e., $>90 \%$ for $S L A$ and $W D,>70 \%$ for $H_{\max }$ and leaf size, $40 \%$ for $K_{\mathrm{s}}$ ).

For each species record, species climatic envelopes were calculated with speciesmap (https://remkoduursma.github.io/speciesmap/articles/Using_speciesmap.html), an R package that combines species occurrences from GBIF (Global Biodiversity Information Facility, http://www.gbif.org), with climate layers from WorldClim (http://www.worldclim.org) and CGIARCSI, cf. Trabucco et al., 2008). speciesmap rasterizes species occurrences and extracts $0.025,0.5$ and 0.975 quantiles for mean annual temperature (MAT), precipitation (MAP) and potential evapotranspiration (PET) across all grid cells of the species occurrence region. Converting the occurrence data into presence/absence grid cells equally weighs over- and under-sampled areas in the climate envelope estimates. Species classification into biomes was obtained from a Whittaker diagram of MAT and MAP (Wright et al. 2004). For those $H_{v}$ measurements where

This article is protected by copyright. All rights reserved. 
Latitude/Longitude were available from the original publications, we compared MAT/MAP at the sampling site against values obtained for the GBIF climate envelope (slope $=0.96, R^{2}=0.94, n=686$, and slope $=0.90, \mathrm{R}^{2}=0.91, \mathrm{n}=686$, for MAT and MAP, respectively; the slopes <1.0 suggest, as expected, a 4-10\% underestimation of MAT/MAP from GBIF relative to local values). Because annual MAP/MAT values may be poorly related to relative water supply particularly during the growing season, a Moisture index (MI) was calculated as MAP/PET. To bring species binomials to a common taxonomy, names were matched against accepted names in The Plant List using taxonstand (Cayuela et al. 2012). Any binomials not found in this list were matched against the International Plant Names Index (IPNI; http:// www.ipni.org/), eFloras and Tropicos (http://www.tropicos.org). The final list with unresolved species nomenclature was carefully checked manually.

\section{Statistical analyses}

To assess functional scaling between variables, bivariate relationships between $H_{v}$ and other traits ( $S L A, M_{\llcorner}, K_{\mathrm{S}}, H_{\max }$ and $W D$ ) were summarised using standardised major axis (SMA) slopes using smatr (Warton et al. 2006). All traits were log-10 transformed to improve residual distribution and examine relationships across order of magnitude differences. Global scaling patterns (i.e., overall line slopes and intercepts $\pm 95 \%$ confidence intervals) were obtained from the fitted regressions. Slopes were compared between categorical groupings by leaf type (broad/needle leaves), leaf shape (simple/compound) leaf habit (winter deciduous/drought deciduous/evergreen), plant growth form (shrub/tree) and taxon group (Angiosperm/Gymnosperm) using a likelihood ratio test (Warton et al. 2006). Where slopes were deemed not to significantly differ, we tested for intercept differences between the common-slope lines and/or shifts of the data clouds along the common-slope line using a Wald test with one degree of freedom (Warton et al. 2006).

Path models (SEM) were used to examine whether the hypothesised correlation structures were consistent with the observed multivariate relationships among traits determining $H_{v}$. We used the sem function in lavaan (Rosseel 2012) and followed Brown (2006) for model selection and diagnostics. $S L A, M_{\mathrm{L}}, H_{\max }$ (in some models also $W D$ and/or $K_{s}$ ) were allowed to co-vary with each other as they jointly affected $H_{v}$. To explore the possibility that these relationships were modulated by additional factors, we allowed for trait covariance to depend on additional categorical variables (i.e., leaf shape, leaf type, plant growth form and taxon group), included as fixed effects in some models. Directed climate effects (MAT, MAP, MI) on leaf, xylem traits and $H_{\max }$ were included in some models, together with directed climate effects on $H_{\mathrm{v}}$. The saturated path models were simplified by removing non-significant paths (using $\mathrm{z}$ tests and $\triangle \mathrm{AIC}$ values) until a minimal adequate

This article is protected by copyright. All rights reserved. 
model was found. Goodness of fit was assessed using absolute fit, parsimony and comparative fit (Brown 2015). Full-information Maximum Likelihood allowed including species with partially missing traits. Finally, the path model coefficients were used to predict $H_{v}$ based on organ-specific traits.

To test whether the relationships of organ traits with $H_{\mathrm{v}}$ were affected by leaf turnover times, the models above were modified to include leaf lifespan LL. Also, as an alternative, we employed leaf habit (deciduous/evergreen) in some models, because the sample size for $L L(n=105$ coupled values of $L L$ and $H_{v}$ ) was much lower than for leaf habit. Leaf habit strongly relates to $L L$ (ttest, $\left.\mathrm{P}=1.1410^{-10}\right)$. Variation in $\mathrm{LL}$ is high among evergreen species, but the consequences for our interpretation are minimal because models with $L L$, leaf habit, or without are almost identical.

To check for the possibility that systematic biases were present across the original datasets (XFT; RAINFOR; TROBIT; Togashi et al., 2015; Niu et al., 2017; Song et al., 2018), we treated these datasets as a random factor in a linear mixed model (nlme, Pinheiro \& Bates, 2000). We modelled $H_{v}$ as a function of leaf and xylem traits, by varying intercept and slope as a function of dataset. We tested the significance of the factor "dataset" by running an ANOVA comparison of the model accounting for dataset as a random factor against a simpler linear model without the random factor. The test showed that the simpler linear model was equally effective $(P=0.9998)$. We therefore discard the possibility that systematic biases across pooled datasets can affect our conclusions, although we acknowledge that study-to-study variability within each dataset is likely. All analyses were carried out in $\mathrm{R}$ version 3.4.3 ( $\mathrm{R}$ Core Team 2017).

\section{Data accessibility}

All data are archived and are available from the TRY plant trait data base: www.try-db.org (https://doi.org/10.1111/j.1365-2486.2011.02451.x).

\section{Results}

In bivariate analyses, $H_{\mathrm{v}}$ scales inversely and with similar correlation strength ( $\mathrm{r}$ from -0.54 to -0.60) with each of the three leaf traits, i.e., $S L A$, individual leaf area $A_{L}$ and individual leaf mass $M_{L}$ (all $\mathrm{P}<2.210^{-16}$, Figure $1 \mathrm{~A}, \mathrm{~B}$ and $\mathrm{C}$, Table 1 ). $H_{\mathrm{v}}$ also scales inversely with xylem specific conductivity $K_{\mathrm{s}}$ and plant stature $H_{\max }$ (Figure $1 \mathrm{D}$ and $\mathrm{E}, \mathrm{r}=-0.53$ and $\mathrm{r}=-0.45$; both $\mathrm{P}<2.210^{-16}$ ). Finally, $H_{\mathrm{v}}$ and $W D$ are positively but poorly related (Figure $1 F, P=0.09, r=0.06$ ). In $\log 10$ scale, $H_{v}$ varies over 3 orders of magnitude, much more than SLA ( $>1$ order), slightly more than $K_{\mathrm{s}}$ and $H_{\max }$ ( $<3$ orders), but less than leaf size (6 orders). Apart from a few gymnosperms, species with very high $H_{v}$ are often

This article is protected by copyright. All rights reserved. 
short shrubs with needle-like leaves in the Proteaceae, Ericaceae, and Asteraceae of the steppes/semi-deserts of South America or Australia. Those with very low $H_{v}$ tend to be large-leaved tall tropical trees in a large number of families (esp., Fabaceae and Malvaceae) in either wet or dry forests. The scaling slope of $H_{v}$ against SLA $(-1.93)$ is far steeper than $-1.0\left(P<2.210^{-16}\right)$. By contrast, the scaling slopes against $M_{\mathrm{L}}$ and $A_{\mathrm{L}}$ are significantly flatter than $-1.0 \quad(\mathrm{~b}=-0.50$ and -0.44 , respectively; $\mathrm{P}<2.210^{-16}$ ). The slopes against $K_{\mathrm{s}}$ and $H_{\max }$ are not significantly different from negative isometry (Table $1, b=-1.04$ and $b=-0.96$, respectively).

Plant growth form (shrub/tree) and taxon group (Angiosperm/Gymnosperm) affect the magnitude but not the direction of these relationships (cf., Figure 1, Table S1). Relative to trees, shrubs are characterised by leaves with lower $S L A$, smaller $A_{\mathrm{L}}$ and $M_{\mathrm{L}}$ and by a xylem with lower $K_{\mathrm{s}}$, while having a higher $H_{v}$ (Figure 1). In contrast, Gymnosperms are shifted vertically downwards and tend to have lower $H_{v}$ for a given $S L A$, leaf size but not $K_{\mathrm{s}}$ relative to Angiosperms (Table S1). For a given stature, shrubs are shifted downward and Gymnosperms upward, relative to Angiosperms. When LL is tested in bivariate relationships, it co-varies positively and significantly with $H_{v}$, but the relationship is weak $(P<0.05, r=0.28)$. Similar results are obtained for leaf habit and $H_{v}(P<0.01$, $r=0.10)$.

Many of the bivariate relationships between $H_{v}, M_{L}, A_{L}, K_{\mathrm{s}}, W D, H_{\max }$ and $S L A$ are affected by various categorical variables (Table S1). Regardless of the specific comparison, the inverse relationships between $H_{v}$ and other traits are conserved, although low sample size makes the relationships non-significant for some groups (needle-like leaves, winter-deciduous plants). Generally, categorical variables related to leaf shape (simple/compound), leaf type (broad/needle leaves) and leaf habit (deciduous/evergreen) are associated with changes in the bivariate slopes between $H_{v}$ and traits. Out of the possible 18 relationships, nine have heterogeneous slopes (cf., Table S1 for the $\mathrm{P}$ slope test values). In contrast, growth form (shrub/tree) and taxon group (Angiosperm/Gymnosperm) are only associated with elevation changes and shifts in data clouds along the common-slope lines (Tables 1 and S1).

SEM analyses (Table S2) confirmed that each of SLA, $M_{\mathrm{L}}, H_{\max }$ and $K_{\mathrm{S}}$ contribute substantially ( $S L A>M_{\mathrm{L}}>K_{\mathrm{s}}>H_{\max }$ ) and independently to variation in $H_{\mathrm{v}}$ (Figure $2 \mathrm{~A}$ ). $H_{\mathrm{v}}$ remains negatively related to $H_{\max }$, leaf $\left(S L A, M_{\mathrm{L}}\right)$ and xylem $\left(K_{\mathrm{S}}\right)$ properties, with this model being strongly supported $(\mathrm{P}=0.697$, Table S2; Figure 2A). All four traits strongly co-vary. In this and subsequent models, substituting $A_{\mathrm{L}}$ for $M_{\llcorner}$leads to almost identical results (data not shown).

This article is protected by copyright. All rights reserved. 
We verified the robustness of the dependency of $H_{v}$ against $H_{\max }$, leaf and xylem traits, by incorporating one additional categorical variable (i.e., taxon group, plant growth form, leaf habit, leaf form, leaf shape) with effects on these traits. In no case do we find that the scaling of $H_{v}$ against leaf/xylem traits disappears or is strongly altered (with the partial exception of the scaling of $H_{\max }$ Figure S3). In all cases, the categorical variables affect the traits directly, while their effects on $H_{v}$ are either very small (Fig. S3E) or non-significant (other panels in Fig. S3). Conversely, highly significant differences in $H_{v}$ are always found across the levels of all these categorical variables using a general linear model (i.e., when trait effects on $H_{v}$ are not accounted for; always $\mathrm{P}<0.0001$; data not shown). When LL is tested with the co-varying leaf/xylem traits, it is not found to be a contributor to $H_{\mathrm{v}}$ and it is excluded ( $P>>0.05)$. Similarly, despite its much larger sample size, leaf habit is not a significant contributor to $H_{v}$ (Fig.S3C).

We also explored the robustness of these relationships to differences in climatic conditions, by incorporating MAT, MAP or MI across the species climatic envelopes (MAP and MAT are highly and positively correlated in our dataset, $P<2.210^{-16}, R^{2}=0.48$ ). Highly significant negative effects of MAT, MAP and $\mathrm{MI}$ are found when tested directly in correlations against $H_{\mathrm{v}}\left(\mathrm{P}<2.210^{-16}, r=-0.49\right.$; $\mathrm{P}<2.210^{-16}, \mathrm{r}=-0.43$, and $\mathrm{P}<2.210^{-16}, \mathrm{r}=-0.28$, respectively). When examined within the network of trait relationships explaining $H_{\mathrm{v}}$, all four plant traits $\left(S L A, M_{\mathrm{L}}, H_{\max }\right.$ and $\left.K_{\mathrm{s}}\right)$ increase at higher MAT, MAP and MI. Interestingly, direct climatic effects on $H_{v}$ are comparatively small or non-existent (Figure 3). In addition, the proportions of explained variance of $H_{v}$ in models with the direct effects of climate on $H_{v}$ are lower than the proportions for the model without climate (i.e., $r^{2}=0.48-0.50$ versus 0.54 , when climate is versus when it is not included, respectively; cf., Fig.2A with Fig. 3). Importantly, the path coefficients from traits to $H_{v}$ change minimally up or down compared to previous models.

Having examined the relationships between $H_{v}$ and $H_{\max }$, leaf and xylem traits, WD was included in the path models. $W D$ co-varies with all four other traits and negatively affects $H_{v}$, contributing to increase the model $r^{2}$ for $H_{v}$ from 0.54 to 0.57 (Table S2, Figure 2B). The direction of the effect of $W D$ on $H_{v}$ remains identical (and its magnitude similar) also with the inclusion of additional categorical variables (data not shown). Overall among all models, the best one explains $57 \%$ of the variance in $H_{v}$ (Figure $S 4$ and Table S2).

This article is protected by copyright. All rights reserved. 
Finally, we examined the performance of a model based only on widely available traits, i.e., excluding the trait with the lowest coverage $\left(K_{S}\right)$ (Figure 4). A model based on $S L A, M_{\mathrm{L}}, H_{\max }$ and $W D$ explains almost the same amount of variance (i.e., 53\%) as the one including xylem conductivity (54\%) and somewhat less compared to the model with all five traits (57\%, cf., Figures 2 and 4), but with comparable standardised root mean square residuals (SRMSR) (Tables S2 and S3).

\section{Discussion}

We provide evidence of consistent global scaling of $H_{v}$ with plant stature, leaf and wood traits. We report relationships robust to the incorporation of climatic variables and major plant groupings, with the best model explaining close to $60 \%$ of the global-scale variability in $H_{v}$ in a sample of $>1,100$ species. By comparison, a regression against MAT and MAP explains only $26 \%$ of the variance of $H_{v}$ (data not shown). This result generalises findings previously reported based on smaller datasets, of relationships between $H_{v}$ and/or $K_{\mathrm{s}}$ with SLA and/or WD (Stratton et al. 2000; Meinzer et al. 2004; Pickup et al. 2005; Gleason et al. 2012; Patiño et al. 2012), of $H_{v}$ with $H_{\max }$ (Liu et al. 2019) and of a negative $H_{\mathrm{v}}-K_{\mathrm{s}}$ relationship (Martínez-Vilalta et al. 2004; Choat et al. 2011; Togashi et al. 2015). Our findings can be employed to improve models' skills for the prediction of vegetation functions in biomes where a lack of empirical data currently limits the parameterization of plant hydraulic processes.

About $40 \%$ of the variance in $H_{v}$ remains unaccounted for in our models. Part of this variance could be explained by variations in the factor $K_{\mathrm{p}} / n$, which is incorporated in Eqn. 2 but is not quantified due to lack of data. Similarly, lack of size ( $A_{x}$, distance from apex, sampling height) measurements prevent us from investigating additional constraints, such as axial variability in $K_{\mathrm{s}}$. Methodological uncertainties for $K_{\mathrm{s}}$ (e.g., Espino \& Schenk 2011) and study-to-study variability in the sampling strategy for $H_{v}$ (leaf and xylem phenology; infrequent use of dyes) add to the same problem. A better understanding of $H_{\mathrm{v}}$ scaling within plants is essential to estimate how leaf/wood allocation can be scaled from branches to whole plants (Mencuccini et al. 2019).

This article is protected by copyright. All rights reserved. 
Covariation between $K_{s}$ and $H_{v}$ in relation to leaf size and SLA

As hypothesised (Eqns. 1-2), $H_{v}$ scales negatively against individual leaf mass $M_{\mathrm{L}}$ (Table 1 , slope of $\sim-0.5)$. Strictly speaking, Equation 2 predicts a scaling of -1.00 , although, as explained above, additional variables may affect this slope. Given the lack of information regarding these variables at the global scale, we refrain from interpreting the discrepancy between predicted and observed exponent of this relationship. It is tempting to explain the scaling between $K_{\mathrm{S}}$ and $M_{\mathrm{L}}$ (or $A_{\mathrm{L}}$; in both cases slope of $\sim 0.5$ ) as a consequence of the longer path length inside longer leaves, leading to greater conduit tapering and larger $K_{\mathrm{s}}$ down the branch. Such analysis should consider the potential covariations with all the other hydraulic variables (cf., Supplementary Information Methods S1 and Whitehead \& Jarvis (1981)). The positive $K_{\mathrm{s}}-M_{\mathrm{L}}$ slope almost exactly matches the negative $H_{\mathrm{v}}-M_{\mathrm{L}}$ slope, effectively leading to an invariance of the product of these two variables (i.e., leaf specific hydraulic conductivity $K_{\mathrm{L}}, K_{\mathrm{L}}=K_{\mathrm{s}} H_{\mathrm{v}}$ ) across leaf sizes (data not shown). Changes in $M_{\mathrm{L}}$ impact on many other functional aspects, including proportion of supporting versus physiologically active tissues (Niinemets et al. 2007), radiation load and boundary layer conductances (Wright et al. 2017). Hence, it is remarkable that no trends are found in the relationship between $M_{\mathrm{L}}$ and $K_{\mathrm{L}}$.

With regard to the $H_{v}-S L A$ relationship, we find a negative slope, consistent with the negative scaling predicted by Eqns. 1-2. The steep slope ( -1.9, Table 1) implies a more-thanproportional decline in $H_{v}$ with $S L A$. Similar to the case above, $K_{\mathrm{s}}$ scales positively against SLA with a slope that is so steep (slope of $\sim 1.6$, Table 1 ) to effectively negate the negative scaling of $H_{\mathrm{v}}$. Hence the increase of $K_{\mathrm{s}}$ with $S L A$ balances the decline of $H_{\mathrm{v}}$ with $S L A$, again leading to no relationship between $S L A$ and leaf-specific conductivity $K_{\mathrm{L}}$ (data not shown). Although the processes leading to these specific scaling exponents are not known, their consequences are apparent. Stomatal conductance and unit-area photosynthetic rates are positively associated with hydraulic capacity in leaves and stems (Mencuccini 2003; Brodribb et al. 2004; Santiago et al. 2004; Scoffoni et al. 2016). All else being equal, high SLA leads to lower $H_{v}$ (Figs. 1 to 4). Hence, without the compensation between $K_{\mathrm{s}}$ and $H_{\mathrm{v}}$ (keeping $K_{\mathrm{L}}$ constant), high-SLA leaves would paradoxically be associated with lower hydraulic capacity and lower unit-area gas exchange, whereas observations show that SLA is unrelated to unit-area photosynthetic rates (Wright et al. 2004, 2005). The general result is that high-SLA (or "acquisitive") leaves are necessarily associated with larger canopy areas (for a given investment in sapwood area), while an absolute increase in xylem $K_{\mathrm{s}}$ helps maintain hydraulic supply to the larger canopy (cf., SI Methods S1). While SLA values obtained from TRY may reflect conditions of partial canopy shading (Keenan \& Niinemets 2016), this is unlikely to lead to different conclusions.

This article is protected by copyright. All rights reserved. 
Overall, cross-species changes in $H_{v}$ against either $M_{\llcorner}$or SLA are compensated for by changes in $K_{\mathrm{s}}$. This is confirmed both by the scaling of $H_{v}$ directly against $K_{\mathrm{s}}$ (negative isometry, i.e., $\mathrm{b}=-1.00$, Table 1, consistent with predictions from Eqns.1-2) and by the fact that the negative relationship between these two variables remains even after accounting for the covariance among traits (Figure 2). Therefore, covariation between $H_{v}$ and $K_{s}$ changes the cross-species balance between conductive areas and specific conductivity per unit area, maintaining similar levels of leaf hydraulic supply (proportional to $K_{\mathrm{L}}$ ) with varying SLA and $M_{\mathrm{L}}$. The existence of a compensation between these two hydraulic properties has been reported already (Ewers \& Fisher 1991; Martínez-Vilalta et al. 2004; Choat et al. 2011; Togashi et al. 2015), but its significance at the global scale had not been realised. While a trade-off between hydraulic efficiency and safety prevents the occurrence of plants with high efficiency and high safety (Gleason et al. 2016), the negative isometric scaling between xylem efficiency and $H_{v}$ separates high relative allocation to a hydraulically inefficient xylem from low allocation to xylem with high hydraulic efficiency. This is similar to the trade-off generally observed across wood types, i.e., from tracheid-based conifer wood to diffuse-porous and ring-porous angiosperm wood. Interestingly, the same scaling is seen also separately for angiosperms and gymnosperms. This compensation justifies a broadly constant leaf-specific hydraulic conductivity $K_{\mathrm{L}}$ with varying $S L A, M_{\mathrm{L}}, W D$ (cf., Table 1) and, as discussed later, plant stature. Other things being equal, a broadly constant $K_{\mathrm{L}}$ allows sustaining similar transpiration rates across species adopting contrasting hydraulic strategies in the same environment (Manzoni et al. 2013).

The regulation of $H_{v}$ by leaf and xylem traits takes place via different processes. In the case of $S L A$, the regulation is assured partly by the mathematical link between these two variables at constant leaf biomass investment (Lloyd et al. 2013; Osnas et al. 2013). The association between SLA and $H_{v}$ therefore links water transport traits to the ecological trade-offs behind LES traits. In the case of $M_{\mathrm{L}}$, the regulation occurs because changes in $M_{\mathrm{L}}$ inevitably lead to changes in total mass investment in leaves, although reductions in leaf numbers $n$ partly compensate increases in $M_{L}$. Therefore, the $M_{\mathrm{L}}-H_{\mathrm{v}}$ effect is mediated via the effect of Corner's rules on leaf packing (Smith et al. 2017). Finally, in the case of the regulation of $H_{v}$ by $K_{s}$, a compensation takes place between investment in thick but inefficient versus thin but efficient xylem. From this perspective, Corner's rules, LES and hydraulic supply to leaves are only partially connected with each other, at least at the global scale chosen for this analysis of species-specific traits.

This article is protected by copyright. All rights reserved. 


\section{The role of plant stature}

Plant stature (i.e., $H_{\max }$ ) is negatively correlated with $H_{\mathrm{v}}$. If the relationship between stature and Huber values was determined by gravity or the need to counter frictional losses during water transport, one would predict a positive effect (cf., Eqn.2). Indeed, this is typically observed within species (i.e., when $H_{v}$ changes during development at constant $H_{\max }$; McDowell et al. 2002). The occurrence of a negative isometric relationship suggests instead that stature brings about the need to reduce relative biomass allocation to sapwood, possibly as a consequence of sapwood carbon costs versus leaf gains (Mencuccini 2003; Niinemets 2010; Anfodillo et al. 2016; Fajardo et al. 2019). This may especially be the case under high competitive (i.e., closed canopy) conditions, where carbon balance may be less favourable (Togashi et al. 2015). Nonetheless, the correlation coefficient of $H_{\max }$ with $H_{\mathrm{v}}$ is lower than for almost all other traits (Table 1). Equivalently, the standardised coefficient for $H_{\max }$ is the lowest among the variables controlling changes in $H_{v}$ in our path models (Figs. 2-4), suggesting that changes in stature are not strongly correlated with sapwood-leaf area ratios, when all the other variables are partialled out. This low correlation is likely caused by the covariation between $H_{\max }$ and other leaf/xylem traits (Liu et al. 2019) and the compensation between $H_{v}$ and $K_{\mathrm{s}}$. In our path models, $K_{\mathrm{s}}$ is negatively related to $H_{\mathrm{v}}$ while it co-varies positively with $H_{\max }$, hence net size effects of $H_{\max }$ on $H_{v}$ are strongly reduced. The overall negative isometric scaling (slope of -1.00 , cf., Table 1 ) between $H_{v}$ and $H_{\max }$ suggests that sapwood volume per unit of leaf area may be conserved across species. However, shrubs had a lower branch-top $H_{v}$ than trees for a given $H_{\max }$ and relationships for each growth form were steeper than negative isometry (Fig.1E, Table S1). The difference between these two growth forms may not have been found, had we examined the relationship of $H_{v}$ with actual $H$ as opposed to $H_{\max }$. Similarly, we did not attempt to employ scaling relationships explicitly accounting for vertical variability in hydraulics with height (e.g., Couvreur et al. 2018).

Isometric scalings were also found for $K_{\mathrm{s}}$ against $H_{\max }$ (slope of +1.00$)$ and $H_{\mathrm{v}}$ against $K_{\mathrm{s}}$ (slope of -1.00$)$. Hence, a broadly constant branch-top leaf-specific hydraulic conductivity $K_{\mathrm{L}}$ is maintained (cf., West et al. 1999), despite the increasing stature of tall trees. This occurs via increases in specific conductivity (likely caused by increased canopy-top conduit diameters, Olson et al. 2014, 2018) and reductions in $H_{v}$, probably to avoid stature-related carbon costs (Mencuccini 2003). Plant stature also co-varies with $M_{\mathrm{L}}$ and with $S L A$, albeit less strongly. Compared to shrubs (most of them, from desert or woodland, not boreal, biomes), tall (mainly tropical) trees are characterised by larger leaves and, less consistently, leaves with high specific leaf area. This also contrasts with trends

This article is protected by copyright. All rights reserved. 
occurring within individual trees, where leaf size and SLA strongly decline with height (Koch et al. 2004; Burgess \& Dawson 2007).

The role of wood density

The negative association between $W D$ and $H_{v}$ was not predicted in our theoretical framework (Eqns.1-2) but is robust to the covariation with other organ-level traits, categorical and climatic variables. A mechanistic interpretation of the role of $W D$ is complicated by its involvement in several processes (cf., discussion in Supplementary Materials Methods S1). The direct negative effect of WD on $H_{v}$ most likely reflects a bio-mechanical / carbon cost trade-off between smaller but denser sapwood areas versus larger areas made up of cheaper wood. This trade-off is probably mediated by the relationships between WD and wood mechanical properties (Chave et al. 2009; Niklas \& Spatz 2010). WD also acts indirectly via conduit size and packing (which leads to negative covariance of $W D$ with $K_{\mathrm{s}}$, cf., derivation in SI, Methods S1) and via its covariances with SLA and $M_{\mathrm{L}}$. WD may also be linked to abundance of fibres, fibre wall thickness and parenchyma wood fractions (Ziemińska et al. 2015). We considered that WD may act on $H_{v}$ via hydraulic safety. This analysis however shows no significant effect of P50 on $H_{v}$ in a path model with the other traits (data not shown).

\section{Climate and other moderating variables}

Within species, $H_{v}$ can respond to climatic conditions, e.g., radiation, site water balance, vapour pressure deficit and/or temperature (Mencuccini \& Grace 1995; Delucia et al. 2000). We confirm these findings globally, with significant cross-species effects of MAT, MAP and MI on $H_{\mathrm{v}}$. One of the most interesting results of our analysis is that, contrary to our initial hypothesis, direct climatic effects on $H_{v}$ become non-significant or very small when the effects of MAT, MAP and MI are tested in a path model, accounting for indirect climatic effects via $H_{\max }$ and leaf/xylem traits. This finding suggests that evolutionary pressure by climate on $H_{v}$ may largely occur via the component traits, e.g., reducing $H_{\max }, K_{\mathrm{s}}, M_{\mathrm{L}}$ and $S L A$ under dry conditions.

This article is protected by copyright. All rights reserved. 


\section{Prediction of hydraulic traits for global models}

Global models increasingly need to be parameterised with wood-to-leaf ratios and hydraulic traits (Fatichi et al. 2016; Matheny et al. 2017; Mencuccini et al. 2019), including $H_{v}$ and $K_{\mathrm{s}}$ specific to different plant functional types. However, adequate parameterisation of hydraulic and biomass scaling in terrestrial biosphere models requires understanding how the relevant traits are integrated and co-vary with one another. A model for sapwood/leaf allocation based entirely on organ-specific traits has the advantage of increasing model consistency and avoid over-parameterization. The fact that the model including only four easily measured and widely available traits ( $S L A, M_{L}, H_{\max }$ and $W D$ ) performs similarly to the models including the less available xylem efficiency $K_{\mathrm{s}}$ raises the possibility that $H_{v}$ may be estimated globally from parameters already employed in models. Additionally, the negative isometric scaling between $H_{v}$ and $K_{\mathrm{s}}$ is robust to several comparisons across potential grouping variables and to the covariation with other traits. Therefore, it may also be possible to predict $K_{\mathrm{s}}$ as a function of $H_{\mathrm{v}}$, assuming a globally constant $K_{\mathrm{L}}$.

Our conclusion that relative allocation to sapwood/leaf area can be explained via component traits is limited to the canopy-top branches where $H_{v}$ was measured. Using the limited available data, Mencuccini et al. (2019) showed that, while varying from species to species, $H_{v}$ tend to remain relatively constant from twig to trunk base. A constant sapwood-leaf ratio along the plant axis is consistent with metabolic scaling theory (West et al. 1999; Savage et al. 2010). However, neither the dataset we previous employed (Mencuccini et al. 2019), nor metabolic scaling theory account for light-dependent variation in traits within tree canopies. In addition, we employed species-level averages to estimate relationships between traits and $H_{\mathrm{v}}$. A complementary approach would be to examine this scaling at ecosystem and biome scales, using available plot-level information on species distributions across biomes. Further investigations are required to determine the robustness of this approach for modelling $H_{v}$ and other hydraulic traits in different plant functional types.

\section{Acknowledgements}

This research was supported by the Spanish Ministry of Economy and Competitiveness (MINECO) via competitive grants CGL2013-46808-R and CGL2017-89149-C2-1-R. TR was supported by a FPI scholarship from MINECO. JMV benefited from an ICREA Academia award. FS acknowledges support from a University of Nottingham Anne McLaren fellowship. We remember S Patiño (deceased) and thank J Lloyd for initially drawing our attention to the RAINFOR and TROBIT field collections of Huber

This article is protected by copyright. All rights reserved. 
values. The data derived from the hydraulics database is partly an outcome from a working group funded by the ARC through the Australia-New Zealand Research Network for Vegetation Function. The study was supported by the TRY initiative on plant traits (www.try-db.org) and relative supporting agencies. SM acknowledges partial support from the Swedish Research Council Formas (2016-00998). We thank three anonymous reviewers for their useful comments. The authors declare no conflict of interest.

\section{Reference List}

Anfodillo, T., Carraro, V., Carrer, M., Fior, C. \& Rossi, S. (2006). Convergent tapering of xylem conduits in different woody species. New Phytol., 169, 279-290.

Anfodillo, T., Petit, G., Sterck, F., Lechthaler, S. \& Olson, M.E. (2016). Allometric trajectories and "stress": A quantitative approach. Front. Plant Sci., 7, 1-6.

Bloom, A.J., Chapin, S.F. \& Mooney, H.A. (1985). Resource limitation in plants- An economic analogy. Annu. Rev. Ecol. Syst., 16, 363-392.

Brodribb, T.J., Holbrook, N.M., Zwieniecki, M.A. \& Palma, B. (2004). Leaf hydraulic capacity in ferns, conifers and angiosperms: impacts on photosynthetic maxima. New Phytol., 165, 839-846.

Brown, T.A. (2015). Confirmatory Factor Analysis for Applied Research. Methodol. Soc. Sci. Second Edi. Guildford Press, New York, London.

Burgess, S.S.O. \& Dawson, T.E. (2007). Predicting the limits to tree height using statistical regression of leaf traits. New Phytol., 174, 626-636.

Castorena, M., Rosell, J.A. \& Olson, M.E. (2015). Trubs, but no trianas: Filled and empty regions of angiosperm stem length-diameter-mechanics space. Bot. J. Linn. Soc., 179, 361-373.

Cayuela, L., Granzow-de la Cerda, Í., Albuquerque, F.S. \& Golicher, D.J. (2012). taxonstand: An r package for species names standardisation in vegetation databases. Methods Ecol. Evol., 3, 1078-1083.

Chave, J., Coomes, D., Jansen, S., Lewis, S.L., Swenson, N.G. \& Zanne, A.E. (2009). Towards a worldwide wood economics spectrum. Ecol. Lett., 12, 351-366.

Choat, B., Jansen, S., Brodribb, T.J., Cochard, H., Delzon, S., Bhaskar, R., et al. (2012). Global convergence in the vulnerability of forests to drought. Nature, 491, 752-755.

Choat, B., Medek, D.E., Stuart, S.A., Pasquet-Kok, J., Egerton, J.J.G., Salari, H., et al. (2011). Xylem traits mediate a trade-off between resistance to freeze-thaw-induced embolism and photosynthetic capacity in overwintering evergreens. New Phytol., 191, 996-1005.

Coleman, J.S., McConnaughay, K.D.M. \& Ackerly, D.D. (1994). Interpreting phenotypic variation in plants. Trends Ecol. Evol., 9, 188-191.

Corner, E.J.H. (1949). The Durian theory or the origin of the modern tree. Ann. Bot., 13, 367-414.

Couvreur, V., Ledder, G., Manzoni, S., Way, D.A., Muller, E.B. \& Russo, S.E. (2018). Water transport through tall trees: A vertically explicit, analytical model of xylem hydraulic conductance in

This article is protected by copyright. All rights reserved. 
stems. Plant. Cell Environ., 41, 1821-1839.

Delucia, E.H., Maherali, H. \& Carey, E. V. (2000). Climate-driven changes in biomass allocation in pines. Glob. Chang. Biol., 6, 587-593.

Díaz, S., Kattge, J., Cornelissen, J.H.C., Wright, I.J., Lavorel, S., Dray, S., et al. (2016). The global spectrum of plant form and function. Nature, 529, 167-171.

Duursma, R.A. \& Falster, D.S. (2016). Leaf mass per area, not total leaf area, drives differences in above-ground biomass distribution among woody plant functional types. New Phytol., 212, 368-376.

Enquist, B.J. \& Niklas, K.J. (2002). Global allocation rules for patterns of biomass partitioning in seed plants. Science (80-. )., 295, 1517-1520.

Espino, S. \& Schenk, H.J. (2011). Mind the bubbles: Achieving stable measurements of maximum hydraulic conductivity through woody plant samples. J. Exp. Bot., 62, 1119-1132.

Ewers, F.W. \& Fisher, J.B. (1991). Why vines have narrow stems: histological trends in Bauhimia (Fabaceae). Oecologia, 88, 233-237.

Fajardo, A., Mclntire, E.J.B. \& Olson, M.E. (2019). When short stature is an asset in trees. Trends Ecol. Evol., 34, 193-199.

Farrior, C.E., Dybzinski, R., Levin, S.A. \& Pacala, S.W. (2013). Competition for water and light in closed-canopy forests: a tractable model of carbon allocation with implications for carbon sinks. Am. Nat., 181, 314-330.

Fatichi, S., Pappas, C. \& Ivanov, V.Y. (2016). Modeling plant-water interactions: an ecohydrological overview from the cell to the global scale. Wiley Interdiscip. Rev. Water, 3, 327-368.

Franklin, O., Johansson, J., Dewar, R.C., Dieckmann, U., McMurtrie, R.E., Brannstrom, A., et al. (2012). Modeling carbon allocation in trees: a search for principles. Tree Physiol., 32, 648-666.

Freschet, G.T., Valverde-Barrantes, O.J., Tucker, C.M., Craine, J.M., McCormack, M.L., Violle, C., et al. (2017). Climate, soil and plant functional types as drivers of global fine-root trait variation. J. Ecol., 105, 1182-1196.

Gill, R.A. \& Jackson, R.B. (2000). Global patterns of root turnover for terrestrial ecosystems. New Phytol., 147, 13-31.

Gleason, S.M., Butler, D.W., Ziemińska, K., Waryszak, P. \& Westoby, M. (2012). Stem xylem conductivity is key to plant water balance across Australian angiosperm species. Funct. Ecol., $26,343-352$.

Gleason, S.M., Westoby, M., Jansen, S., Choat, B., Hacke, U.G., Pratt, R.B., et al. (2016). Weak tradeoff between xylem safety and xylem-specific hydraulic efficiency across the world's woody plant species. New Phytol., 209, 123-136.

Grime, J.P. (1979). Plant Strategies and Vegetation Processes. John Wiley and Sons, New York.

Hacke, U.G., Sperry, J.S., Pockman, W.T., Davis, S.D. \& McCulloh, K.A. (2001). Trends in wood density and structure are linked to prevention of xylem implosion by negative pressure. Oecologia, $126,457-461$.

Hodgson, J.G., Santini, B.A., Montserrat Marti, G., Royo Pla, F., Jones, G., Bogaard, A., et al. (2017). Trade-offs between seed and leaf size (seed-phytomer-leaf theory): functional glue linking regenerative with life history strategies ... and taxonomy with ecology? Ann. Bot., 120, 633-

This article is protected by copyright. All rights reserved. 
652.

Hunt, R. \& Cornelissen, J.H.C.C. (1997). Components of relative growth rate and their interrelations in 59 temperate plant species. New Phytol., 135, 395-417.

Kattge, J., Diaz, S., Lavorel, S., Prentice, I.C., Leadley, P., Bonisch, G., et al. (2011). TRY - a global database of plant traits. Glob. Chang. Biol., 17, 2905-2935.

Keenan, T.F. \& Niinemets, Ü. (2016). Global leaf trait estimates biased due to plasticity in the shade. Nat. Plants, 3, 16201.

Kikuzawa, K. (1991). A cost-benefit analysis of leaf habit and leaf longevity of trees and their geographical pattern. Am. Nat., 138, 1250-1263.

Kleiman, D. \& Aarssen, L.W. (2007). The leaf size/number trade-off in trees. J. Ecol., 95, 376-382.

Koch, G.W., Sillet, S.C., Jennings, G.M. \& Davis, S.D. (2004). The limits to tree height. Nature, 428, 851-854.

Lapenis, A., Shvidenko, A., Shepaschenko, D., Nilsson, S. \& Aiyyer, A. (2005). Acclimation of Russian forests to recent changes in climate. Glob. Chang. Biol., 11, 2090-2102.

Ledo, A., Paul, K.I., Burslem, D.F.R.P., Ewel, J.J., Barton, C., Battaglia, M., et al. (2017). Tree size and climatic water deficit control root to shoot ratio in individual trees globally. New Phytol., 217, 8-11.

Liu, H., Gleason, S.M., Hao, G., Hua, L., He, P., Goldstein, G., et al. (2019). Hydraulic traits are coordinated with maximum plant height at the global scale. Sci. Adv., 5, eaav1332.

Lloyd, J., Bloomfield, K., Domingues, T.F. \& Farquhar, G.D. (2013). Photosynthetically relevant foliar traits correlating better on a mass vs an area basis: of ecophysiological relevance or just a case of mathematical imperatives and statistical quicksand? New Phytol., 199, 311-321.

Manzoni, S., Vico, G., Katul, G., Palmroth, S., Jackson, R.B. \& Porporato, A. (2013). Hydraulic limits on maximum plant transpiration and the emergence of the safety-efficiency trade-off. New Phytol., 198, 169-178.

Martínez-Vilalta, J., Sala, A. \& Piñol, J. (2004). The hydraulic architecture of Pinaceae - a review. Plant Ecol., 171, 3-13.

Matheny, A.M., Mirfenderesgi, G. \& Bohrer, G. (2017). Trait-based representation of hydrological functional properties of plants in weather and ecosystem models. Plant Divers., 39, 1-12.

McCarthy, M.C. \& Enquist, B.J. (2007). Consistency between an allometric approach and optimal partitioning theory in global patterns of plant biomass allocation. Funct. Ecol., 21, 713-720.

McDowell, N., Barnard, H., Bond, B.J., Hinckley, T., Hubbard, R.M., Ishii, H., et al. (2002). The relationship between tree height and leaf area: Sapwood area ratio. Oecologia, 132, 12-20.

Meinzer, F.C., Brooks, J.R., Bucci, S., Goldstein, G., Scholz, F.G. \& Warren, J.M. (2004). Converging patterns of uptake and hydraulic redistribution of soil water in contrasting woody vegetation types. Tree Physiol., 24, 919-28.

Mencuccini, M. (2002). Hydraulic constraints in the functional scaling of trees. Tree Physiol., 22, 553565.

Mencuccini, M. (2003). The ecological significance of long-distance water transport: short-term regulation, long-term acclimation and the hydraulic costs of stature across plant life forms. Plant. Cell Environ., 26, 163-182.

This article is protected by copyright. All rights reserved. 
Mencuccini, M. \& Grace, J. (1995). Climate influences the leaf area/sapwood area ratio in Scots pine. Tree Physiol., 15, 1-10.

Mencuccini, M., Manzoni, S. \& Christoffersen, B. (2019). Modelling water fluxes in plants: from tissues to biosphere. New Phytol., 222, 1207-1222.

Mitchell, P.J., Veneklaas, E.J., Lambers, H. \& Burgess, S.S.O. (2008). Using multiple trait associations to define hydraulic functional types in plant communities of south-western Australia. Oecologia, 158, 385-397.

Niinemets, Ü. (1999). Components of leaf dry mass per area - thickness and density - alter leaf photosynthetic capacity in reverse directions in woody plants. New Phytol., 144, 35-47.

Niinemets, Ü. (2001). Global-scale climatic controls of leaf dry mass per area, density, and thickness in trees and shrubs. Ecology, 82, 453-469.

Niinemets, Ü. (2010). A review of light interception in plant stands from leaf to canopy in different plant functional types and in species with varying shade tolerance. Ecol. Res., 25, 693-714.

Niinemets, Ü., Keenan, T.F. \& Hallik, L. (2015). A worldwide analysis of within-canopy variations in leaf structural, chemical and physiological traits across plant functional types. New Phytol., 205, 973-993.

Niinemets, Ü., Portsmuth, A., Tena, D., Tobias, M., Matesanz, S. \& Valladares, F. (2007). Do we underestimate the importance of leaf size in plant economics? Disproportional scaling of support costs within the spectrum of leaf physiognomy. Ann. Bot., 100, 283-303.

Niklas, K.J. \& Spatz, H.C. (2006). Allometric theory and the mechanical stability of large trees: Proof and conjecture. Am. J. Bot., 93, 824-828.

Niklas, K.J. \& Spatz, H.C. (2010). Worldwide correlations of mechanical properties and green wood density. Am. J. Bot., 97, 1587-1594.

Niu, C.-Y., Meinzer, F.C. \& Hao, G.-Y. (2017). Divergence in strategies for coping with winter embolism among co-occurring temperate tree species: the role of positive xylem pressure, wood type and tree stature. Funct. Ecol., 31, 1550-1560.

Olson, M.E., Aguirre-Hernández, R. \& Rosell, J.A. (2009). Universal foliage-stem scaling across environments and species in dicot trees: Plasticity, biomechanics and Corner's Rules. Ecol. Lett., $12,210-219$.

Olson, M.E., Anfodillo, T., Rosell, J.A., Petit, G., Crivellaro, A., Isnard, S., et al. (2014). Universal hydraulics of the flowering plants: Vessel diameter scales with stem length across angiosperm lineages, habits and climates. Ecol. Lett., 17, 988-997.

Olson, M.E., Soriano, D., Rosell, J.A., Anfodillo, T., Donoghue, M.J., Edwards, E.J., et al. (2018). Plant height and hydraulic vulnerability to drought and cold. Proc. Natl. Acad. Sci. USA, 115, 75517556.

Osnas, J.L.D., Lichstein, J.W., Reich, P.B. \& Pacala, S.W. (2013). Global leaf trait relationships: Mass, area, and the leaf economics spectrum. Science (80-. )., 340, 741-744.

Patiño, S. (2005). Manual de campo para el estudio de hojas y madera editado para establecer efectos de sequías. Proyecto Pan-Amazonia, EU, Sixth Framework Programme 12 pp., Leeds, United Kingdom.

Patiño, S., Fyllas, N.M., Baker, T.R., Paiva, R., Quesada, C.A., Santos, A.J.B., et al. (2012). Coordination of physiological and structural traits in Amazon forest trees. Biogeosciences, 9, 775-801.

This article is protected by copyright. All rights reserved. 
Pickup, M., Westoby, M. \& Basden, A. (2005). Dry mass costs of deploying leaf area in relation to leaf size. Funct. Ecol., 19, 88-97.

Pierce, S., Negreiros, D., Cerabolini, B.E.L., Kattge, J., Díaz, S., Kleyer, M., et al. (2017). A global method for calculating plant CSR ecological strategies applied across biomes world-wide. Funct. Ecol., 31, 444-457.

Pinheiro, J.C. \& Bates, D.M. (2000). Mixed-Effects Models in S and S-PLUS. Springer-Verlag New York Berlin Heidelberg.

Poorter, H., Jagodzinski, A.M., Ruiz-Peinado, R., Kuyah, S., Luo, Y., Oleksyn, J., et al. (2015). How does biomass distribution change with size and differ among species? An analysis for 1200 plant species from five continents. New Phytol., 208, 736-749.

Poorter, H., Niinemets, Ü., Ntagkas, N., Siebenkäs, A., Mäenpää, M., Matsubara, S., et al. (2019). A meta-analysis of plant responses to light intensity for 70 traits ranging from molecules to whole plant performance. New Phytol., https://doi.org/10.1111/nph.15754.

Poorter, H., Niklas, K.J., Reich, P.B., Oleksyn, J., Poot, P. \& Mommer, L. (2012). Biomass allocation to leaves, stems and roots: meta-analysis of interspecific variation and environmental control. New Phytol., 193, 30-50.

R Core Team. (2017). R: A language and environment for statistical computing. Vienna, Austria. R Foundation for Statistical Computing. R version 3.5.0. https://www.r-project.org/.

Reich, P.B. (2002). Root-shoot relations: optimality in acclimation and adaptation or the 'Emperor's New Clothes'? In: Plant Roots: The Hidden Half (eds. Waisel, Y., Amram, E. \& Kafkafi, U.). Marcel Dekker, New York, pp. 205-220.

Reich, P.B., Luo, Y., Bradford, J.B., Poorter, H., Perry, C.H. \& Oleksyn, J. (2014a). Temperature drives global patterns in forest biomass distribution in leaves, stems, and roots. Proc. Natl. Acad. Sci. U. S. A., 111, 13721-13726.

Reich, P.B., Rich, R.L., Lu, X., Wang, Y.-P. \& Oleksyn, J. (2014b). Biogeographic variation in evergreen conifer needle longevity and impacts on boreal forest carbon cycle projections. Proc. Natl. Acad. Sci. U. S. A., 111, 13703-13708.

Reich, P.B., Walters, M.B. \& Ellsworth, D.S. (1997). From tropics to tundra: Global convergence in plant functioning. Proc. Natl. Acad. Sci. U. S. A., 94, 13730-13734.

Rosseel, Y. (2012). lavaan: An R package for structural equation modeling. J. Stat. Softw., 48, 1-36.

Santiago, L.S., Goldstein, G., Meinzer, F.C., Fisher, J.B., Machado, K., Woodruff, D., et al. (2004). Leaf photosynthetic traits scale with hydraulic conductivity and wood density in Panamanian forest canopy trees. Oecologia, 140, 543-550.

Savage, V.M., Bentley, L.P., Enquist, B.J., Sperry, J.S., Smith, D.D., Reich, P.B., et al. (2010). Hydraulic trade-offs and space filling enable better predictions of vascular structure and function in plants. Proc. Natl. Acad. Sci. USA, 107, 22722-7.

Schrodt, F., Domingues, T.F., Feldpausch, T.R., Saiz, G., Quesada, C.A., Schwarz, M., et al. (2015). Foliar trait contrasts between African forest and savanna trees: Genetic versus environmental effects. Funct. Plant Biol., 42, 63-83.

Scoffoni, C., Chatelet, D.S., Pasquet-kok, J., Rawls, M., Donoghue, M.J., Edwards, E.J., et al. (2016). Hydraulic basis for the evolution of photosynthetic productivity. Nat. Plants, 2, 16072.

Shipley, B. (2006). Net assimilation rate, specific leaf area and leaf mass ratio: Which is most closely

This article is protected by copyright. All rights reserved. 
correlated with relative growth rate? A meta-analysis. Funct. Ecol., 20, 565-574.

Shipley, B., Lechowicz, M.J., Wright, I. \& Reich, P.B. (2006). Fundamental trade-offs generating the worldwide leaf economics spectrum. Ecology, 87, 535-541.

Smith, D.D., Sperry, J.S. \& Adler, F.R. (2017). Convergence in leaf size versus twig leaf area scaling: do plants optimize leaf area partitioning? Ann. Bot., 119, 447-456.

Song, J., Yang, D., Niu, C.-Y., Zhang, W.-W., Wang, M. \& Hao, G.-Y. (2018). Correlation between leaf size and hydraulic architecture in five compound-leaved tree species of a temperate forest in NE China. For. Ecol. Manage., 418, 63-72.

Stratton, L., Goldstein, G. \& Meinzer, F.C. (2000). Stem water storage capacity and efficiency of water transport: their functional significance in a Hawaiian dry forest. Plant, Cell Environ., 23, 99-106.

Thornley, J.H.M. (1972). A balanced quantitative model for root:shoot ratios in vegetative plants. Ann. Bot., 36, 431-441.

Tilman, D. (1988). Plant Strategies and the Dynamics and Structure of Plant Communities. Princeton University Press, Princeton, NJ, USA, 376 pp.

Togashi, H.F., Prentice, I.C., Evans, B.J., Forrester, D.I., Drake, P., Feikema, P., et al. (2015). Morphological and moisture availability controls of the leaf area-to-sapwood area ratio: analysis of measurements on Australian trees. Ecol. Evol., 5, 1263-1270.

Trabucco, A., Zomer, R.J., Bossio, D.A., van Straaten, O. \& Verchot, L. V. (2008). Climate change mitigation through afforestation/reforestation: A global analysis of hydrologic impacts with four case studies. Agric. Ecosyst. Environ., 126, 81-97.

Tyree, M.T. \& Ewers, F.W. (1991). The hydraulic architecture of trees and other woody plants. New Phytol., 119, 345-360.

Warton, D.I., Wright, I.J., Falster, D.S. \& Westoby, M. (2006). Bivariate line-fitting methods for allometry. Biol. Rev., 81, 259-291.

West, G.B., Brown, J.H. \& Enquist, B.J. (1999). A general model for the structure and allometry of plant vascular systems. Nature, 400, 664-667.

Westoby, M. (1998). A leaf-height-seed (LHS) plant ecology strategy scheme. Plant Soil, 199, 213227.

Westoby, M. \& Wright, I.J. (2003). The leaf size - twig size spectrum and its relationship to other important spectra of variation among species. Oecologia, 135, 621-628.

Whitehead, D. \& Jarvis, P.G. (1981). Coniferous forests and plantations. In: Water Deficits and Plant Growth (ed. Kozlowski, T.T.). Academic Press, New York, pp. 49-152.

Wright, I.J., Dong, N., Maire, V., Prentice, I.C., Westoby, M., Díaz, S., et al. (2017). Global climatic drivers of leaf size. Science (80-. )., 357, 917-921.

Wright, I.J., Reich, P.B., Cornelissen, J.H.C., Falster, D.S., Garnier, E., Hikosaka, K., et al. (2005). Assessing the generality of global leaf trait relationships. New Phytol., 166, 485-496.

Wright, I.J., Reich, P.B., Westoby, M., Ackerly, D.D., Baruch, Z., Bongers, F., et al. (2004). The worldwide leaf economics spectrum. Nature, 428, 821-827.

Wu, J., Albert, L.P., Lopes, A.P., Restrepo-Coupe, N., Hayek, M., Wiedemann, K.T., et al. (2016). Leaf development and demography explain photosynthetic seasonality in Amazon evergreen

This article is protected by copyright. All rights reserved. 
forests. Science (80-. )., 351, 972-976.

Zanne, A.E., Tank, D.C., Cornwell, W.K., Eastman, J.M., Smith, S.A., Fitzjohn, R.G., et al. (2014). Three keys to the radiation of angiosperms into freezing environments. Nature, 506, 89-92.

Zhu, S.-D., Song, J.-J., Li, R.-H. \& Ye, Q. (2013). Plant hydraulics and photosynthesis of 34 woody species from different successional stages of subtropical forests. Plant. Cell Environ., 36, 879891.

Ziemińska, K., Westoby, M. \& Wright, I.J. (2015). Broad anatomical variation within a narrow wood density range-A study of twig wood across 69 Australian angiosperms. PLoS One, 10, e0124892.

Zimmermann, M.H. (1983). Xylem Structure and the Ascent of Sap. Springer, Berlin Heidelberg.

Supporting Information.

Supporting Information may be found online in the Supporting Information section at the end of the article.

Table S1. Standardised Major Axis analyses of plant traits in relation to Huber Value.

Table S2. First path Model analysis of leaf and xylem traits in relation to Huber Value.

Table S3. Second path Model analysis of leaf and xylem traits in relation to Huber Value

Figure S1. Plot of the approximate sampling locations for Huber values.

Figure S2. Box-and-whisker plot of Huber values distribution by biome.

Figure S3. Results of the path model explaining Huber values based on traits and additional categorical variables.

Figure S4. Relationship between observed and predicted Huber values for the best-performing model.

Methods S1. Derivation of the inverse relationship between $\mathrm{Hv}$ and xylem specific conductivity Ks and effects of wood density on Ks

This article is protected by copyright. All rights reserved. 
Table 1. Results of Standardised Major Axis analyses of the bivariate relationships among the plant traits affecting $H_{\mathrm{v}}$.

\begin{tabular}{|c|c|c|c|c|c|c|c|c|}
\hline$x_{2}$ & $X_{1}$ & $\begin{array}{c}\mathrm{Y}- \\
\text { Intercept }\end{array}$ & $\begin{array}{c}95 \% \mathrm{Cl} \text { of the } \\
\text { elevation }\end{array}$ & $\begin{array}{c}\text { Slope } \\
(95 \% \mathrm{Cl})\end{array}$ & $\begin{array}{l}95 \% \mathrm{Cl} \text { of the } \\
\text { slope }\end{array}$ & $\mathrm{n}$ & $|r|$ & $\begin{array}{c}(\mathrm{P} \\
\text { value })\end{array}$ \\
\hline$H_{\mathrm{v}}$ & $S L A$ & 2.126 & $2.021 / 2.231$ & -1.934 & $-2.041 /-1.833$ & 1039 & 0.60 & $<2.210^{-16}$ \\
\hline$H_{\mathrm{v}}$ & $A_{\mathrm{L}}$ & 0.874 & $0.824 / 0.923$ & -0.442 & $-0.470 /-0.416$ & 822 & 0.60 & $<2.210^{-16}$ \\
\hline$H_{\mathrm{v}}$ & $M_{\mathrm{L}}$ & 0.459 & $0.422 / 0.497$ & -0.497 & $-0.532 /-0.464$ & 780 & 0.54 & $<2.210^{-16}$ \\
\hline$H_{\mathrm{v}}$ & $K_{\mathrm{s}}$ & 0.481 & $0.432 / 0.531$ & -1.039 & $-1.126 /-0.960$ & 448 & 0.53 & $<2.210^{-16}$ \\
\hline$H_{\mathrm{v}}$ & $H_{\max }$ & 1.413 & $1.339 / 1.486$ & -0.963 & $-1.021 /-0.908$ & 798 & 0.45 & $<2.210^{-16}$ \\
\hline$H_{\mathrm{v}}$ & $W D$ & 1.118 & 1.045 / 1.192 & 1.721 & $1.608 / 1.842$ & 1018 & 0.06 & 0.09 \\
\hline$K_{\mathrm{s}}$ & $S L A$ & -1.300 & $-1.450 /-1.151$ & 1.601 & $1.458 / 1.758$ & 397 & 0.35 & $4.910^{-12}$ \\
\hline$K_{\mathrm{s}}$ & $A_{\mathrm{L}}$ & -0.326 & $-0.415 /-0.236$ & 0.494 & $0.438 / 0.557$ & 218 & 0.48 & $2.510^{-13}$ \\
\hline$K_{\mathrm{s}}$ & $M_{\mathrm{L}}$ & 0.145 & $0.075 / 0.215$ & 0.557 & $0.492 / 0.632$ & 208 & 0.45 & $2.010^{-11}$ \\
\hline$K_{\mathrm{s}}$ & $W D$ & -0.667 & $-0.774 /-0.560$ & -1.673 & $-1.845 /-1.514$ & 386 & 0.18 & 0.0006 \\
\hline$K_{\mathrm{s}}$ & $H_{\max }$ & -0.879 & $-0.994 /-0.764$ & 1.004 & $0.913 / 1.104$ & 316 & 0.30 & $7.110^{-8}$ \\
\hline$M_{\mathrm{L}}$ & $S L A$ & -3.622 & $-3.943 /-3.300$ & 4.101 & 3.802 / 4.424 & 780 & 0.30 & $8.810^{-14}$ \\
\hline$M_{\mathrm{L}}$ & $A_{\mathrm{L}}$ & -0.869 & $-0.896 /-0.842$ & 0.911 & $0.896 / 0.927$ & 780 & 0.98 & $<2.210^{-16}$ \\
\hline$M_{\mathrm{L}}$ & $W D$ & -1.019 & $-1.170 /-0.867$ & -3.022 & $-3.277 /-2.787$ & 74 & 0.18 & $2.510^{-5}$ \\
\hline$M_{\mathrm{L}}$ & $H_{\max }$ & -2.276 & $-2.481 /-2.071$ & 2.173 & $2.026 / 2.330$ & 598 & 0.48 & $<2.210^{-16}$ \\
\hline SLA & & 0.676 & 705 & 0.222 & 238 & 80 & 0.44 & $<2.210^{-16}$ \\
\hline$S L A$ & $W D$ & 0.477 & $0.438 / 0.516$ & -0.956 & $-1.021 /-0.894$ & 976 & 0.29 & $6.410^{-16}$ \\
\hline$S L A$ & $H_{\max }$ & 0.323 & $0.277 / 0.369$ & 0.539 & $0.505 / 0.575$ & 754 & 0.38 & $<2.210^{-16}$ \\
\hline$W D$ & $A_{\mathrm{L}}$ & -0.060 & $-0.105 /-0.015$ & -0.296 & $-0.320 /-0.273$ & 759 & 0.20 & $9.310^{-7}$ \\
\hline$W D$ & $H_{\max }$ & 0.236 & $0.179 / 0.293$ & -0.609 & $-0.652 /-0.569$ & 722 & 0.23 & $2.410^{-10}$ \\
\hline$A_{\mathrm{L}}$ & $H_{\max }$ & -1.369 & $-1.568 /-1.169$ & 2.260 & $2.116 / 2.414$ & 638 & 0.53 & $<2.210^{-16}$ \\
\hline
\end{tabular}

All variables are base-10 log-transformed. Formulas are given as: $\mathrm{X}_{2}=f\left(\mathrm{X}_{1}\right)$. Legend: $\mathrm{Cl}$, confidence intervals; $H_{v}$, Huber value; SLA, Specific Leaf Area; $A_{\mathrm{L}}$, leaf area; $M_{\mathrm{L}}$, leaf mass; $K_{\mathrm{S}}$, xylem specific conductivity; $H_{\max }$, maximum plant height; $W D$, wood density. Sample size (n), correlation coefficient $(r)$ and probability level ( $P$ value) for each regression are also given.

This article is protected by copyright. All rights reserved. 


\section{Figure legends.}

Figure 1. Bivariate plots of Huber Value $H_{v}$ against other plant traits, i.e., A) specific leaf area (SLA), B) leaf area $\left(A_{\llcorner}\right)$, C) leaf mass $\left(M_{\llcorner}\right)$and D) xylem specific conductivity $\left(K_{\mathrm{s}}\right)$, E) plant stature $\left(H_{\max }\right)$ and F) wood density $(W D)$. All variables are base-10 log-transformed. Points are coloured to distinguish Gymnosperms (black triangles) from Angiosperms (circles), and among these, trees (red circles) from shrubs (blue circles). The thin black dashed line gives the overall model II regression scaling across all data points (cf., Table 1). Thick black, blue and red lines give separate scaling for the three respective groups. Statistics of the regressions and the comparisons among groups (shrub vs. trees; Angiosperms vs. Gymnosperms) are given in Supporting Information Table S1.

Figure 2. Results of the Path models explaining Huber Value $\left(H_{v}\right)$ based on A) specific leaf area $(S L A)$, leaf mass $\left(M_{\mathrm{L}}\right)$, plant stature $\left(H_{\max }\right)$ and xylem specific conductivity $\left(K_{\mathrm{s}}\right)$ or $\left.\mathrm{B}\right)$ the same variables plus wood density $(W D)$. Data from both angiosperms and gymnosperms are included. All variables are base-10 log-transformed. All coefficients are standardised. Green single-headed lines (and respective numbers) indicate positive relationships, red single-headed lines (and numbers), negative relationships (from cause to effect). Double-headed arrows (and numbers) indicate covariances among variables. The thicknesses of the lines are proportional to the intensity of the effect. Green numbers close to the rounded arrows around each rectangle give the proportion of unexplained variance for each model (values of 1 are given for the predictor variables). The difference between observed and modelled covariance structure is not significant in either of the two models based on a chi-square test ( $P=0.697$ and $P=0.727$, respectively).

Figure 3. Results of the Path model explaining Huber values $\left(H_{v}\right)$ based on specific leaf area $(S L A)$, leaf mass $\left(M_{\mathrm{L}}\right)$, xylem specific conductivity $\left(K_{\mathrm{s}}\right)$, plant stature $\left(H_{\max }\right)$ and climatic variables. Plots give the relative fits for A) mean annual temperature MAT, B) mean annual precipitation MAP and C) moisture index $\mathrm{MI}$ (ratio of precipitation to potential evapotranspiration). All variables are log10transformed. All coefficients are standardised to vary between 0 and 1. Green lines and numbers indicate positive relationships, red lines and numbers, negative relationships. Double-headed arrows indicate covariance among variables. The thicknesses of the lines are proportional to the intensity of the effect. Green numbers close to the rounded arrows around each rectangle give the proportion of unexplained variance for each model. Observed and modelled covariance structure were not significantly different in any of the models, based on a chi-square test $(P=0.461, P=0.227$ and $P=0.294$, respectively, from $A-C)$.

This article is protected by copyright. All rights reserved. 
Figure 4. Results of the Path model explaining Huber Value $\left(H_{\mathrm{v}}\right)$ based on specific leaf area (SLA), individual leaf mass $\left(M_{\mathrm{L}}\right)$, plant stature $\left(H_{\max }\right)$ and wood density $(W D)$. All variables are base-10 logtransformed. All coefficients are standardised. Green single-headed lines (and respective numbers) indicate positive relationships, red single-headed lines (and numbers), negative relationships (from cause to effect). Double-headed arrows (and numbers) indicate covariances among variables. The thicknesses of the lines are proportional to the intensity of the effect. Green numbers close to the rounded arrows around each rectangle give the proportion of unexplained variance for each model (values of 1 are given for the predictor variables). The difference between observed and modelled covariance structure is not significant based on a chi-square test $(P=0.469)$.
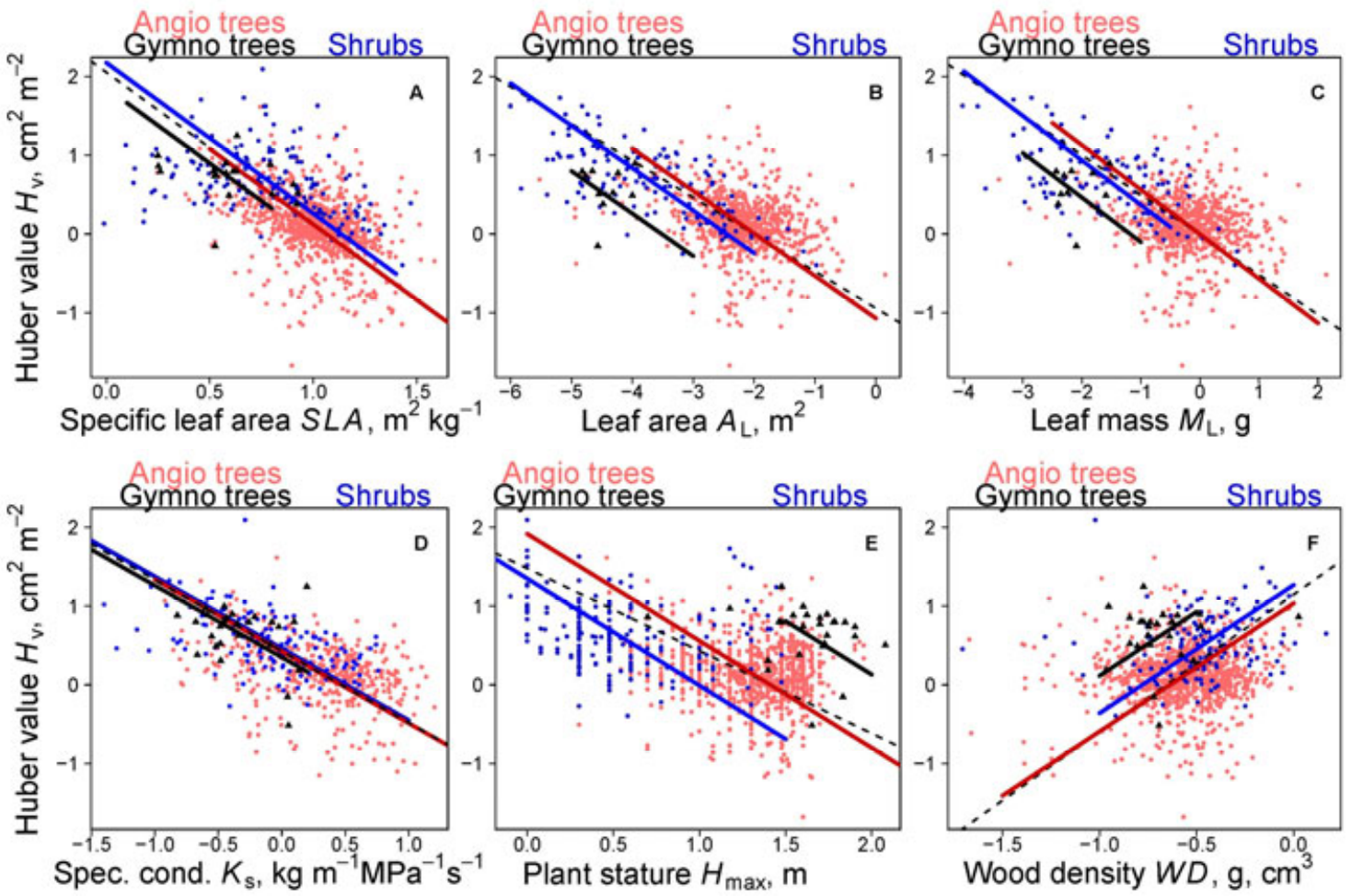

This article is protected by copyright. All rights reserved. 


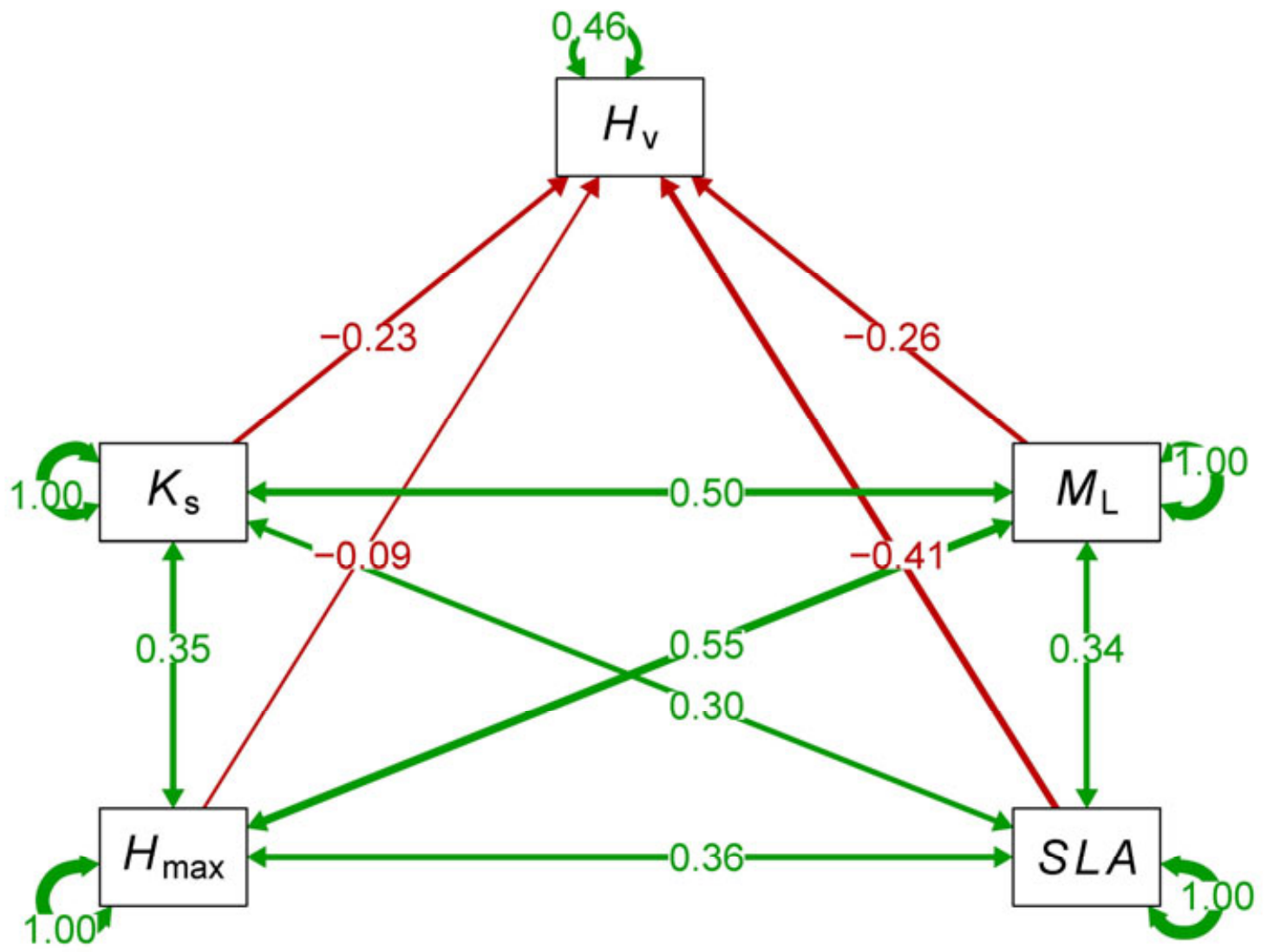

This article is protected by copyright. All rights reserved. 


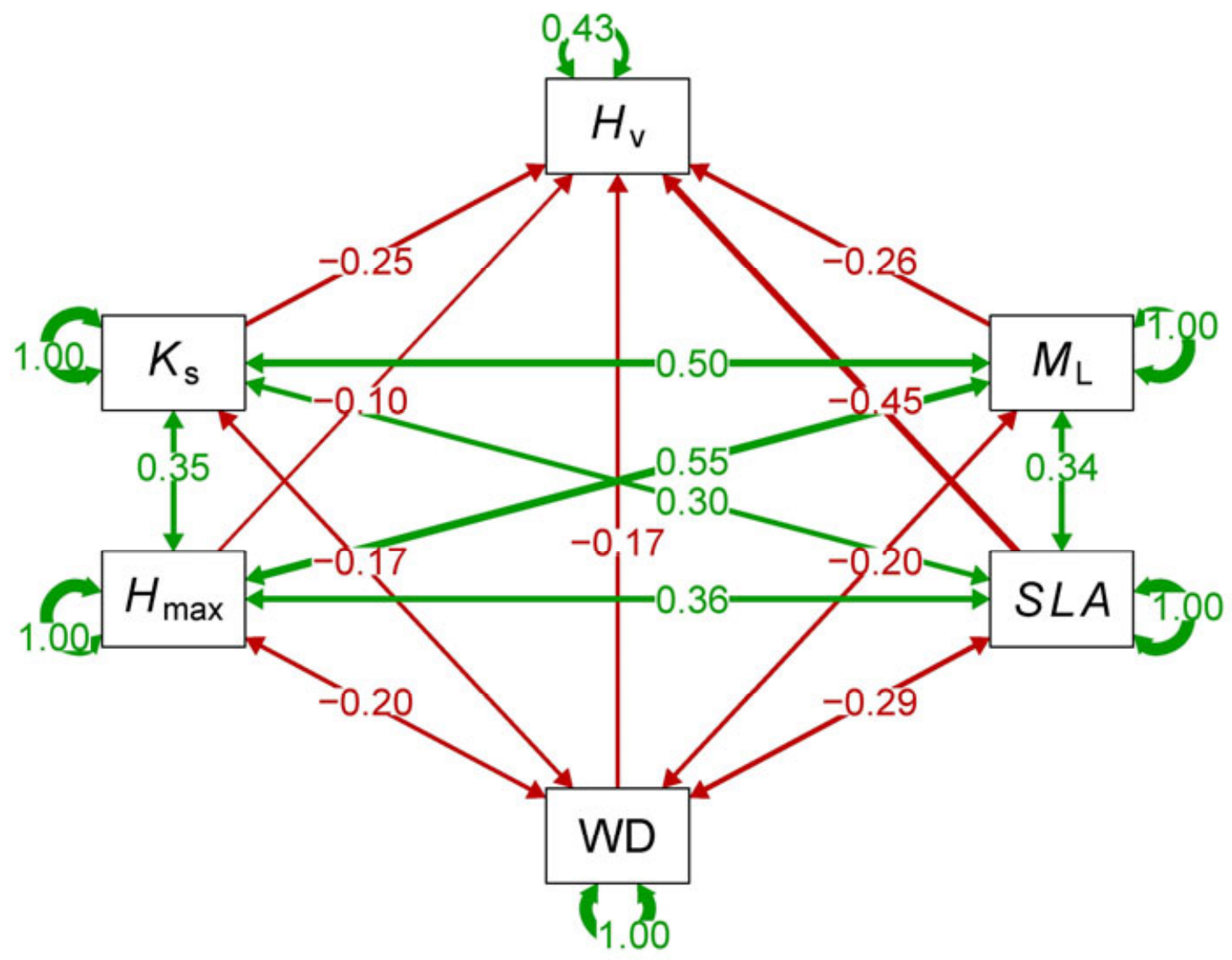

This article is protected by copyright. All rights reserved. 


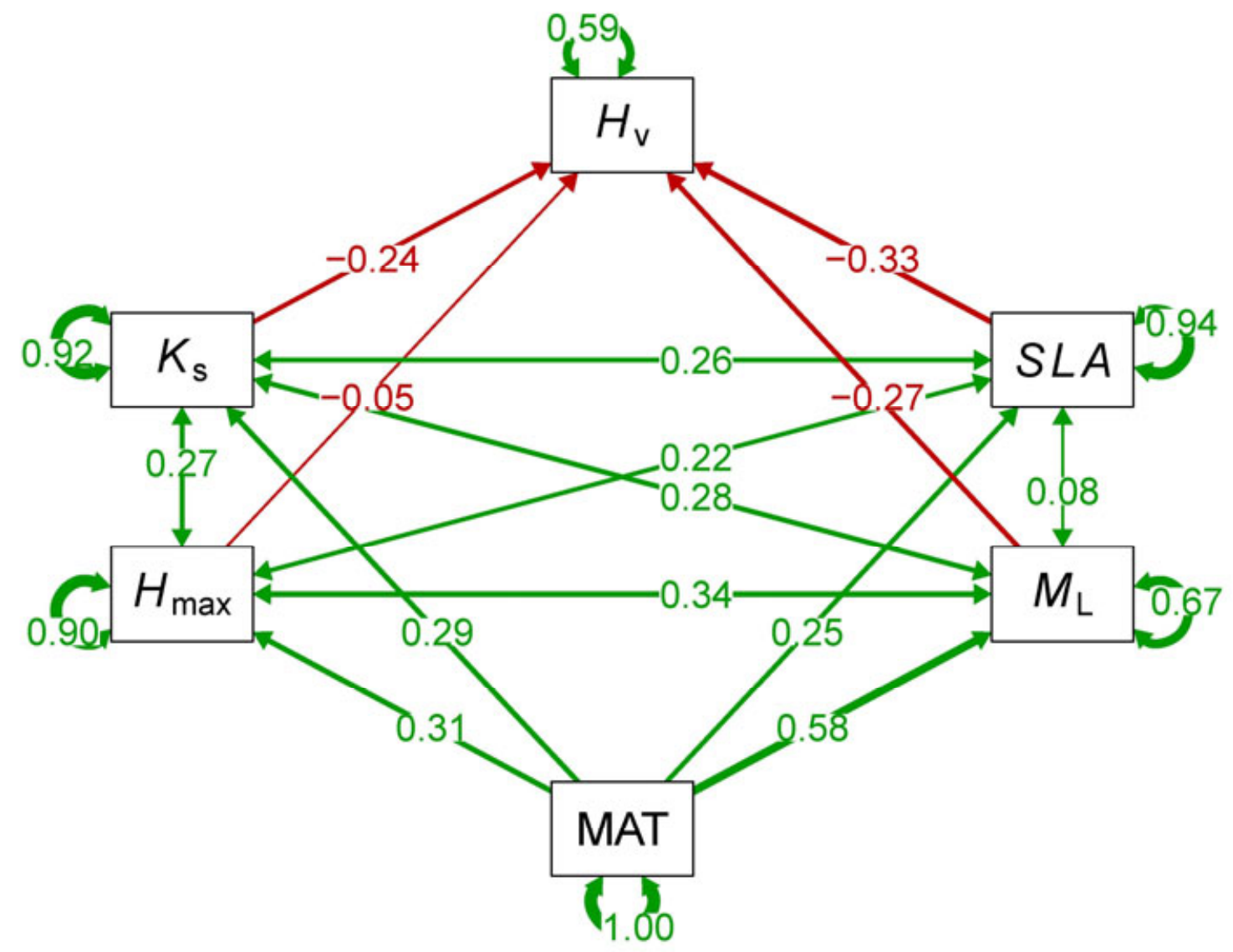

This article is protected by copyright. All rights reserved. 


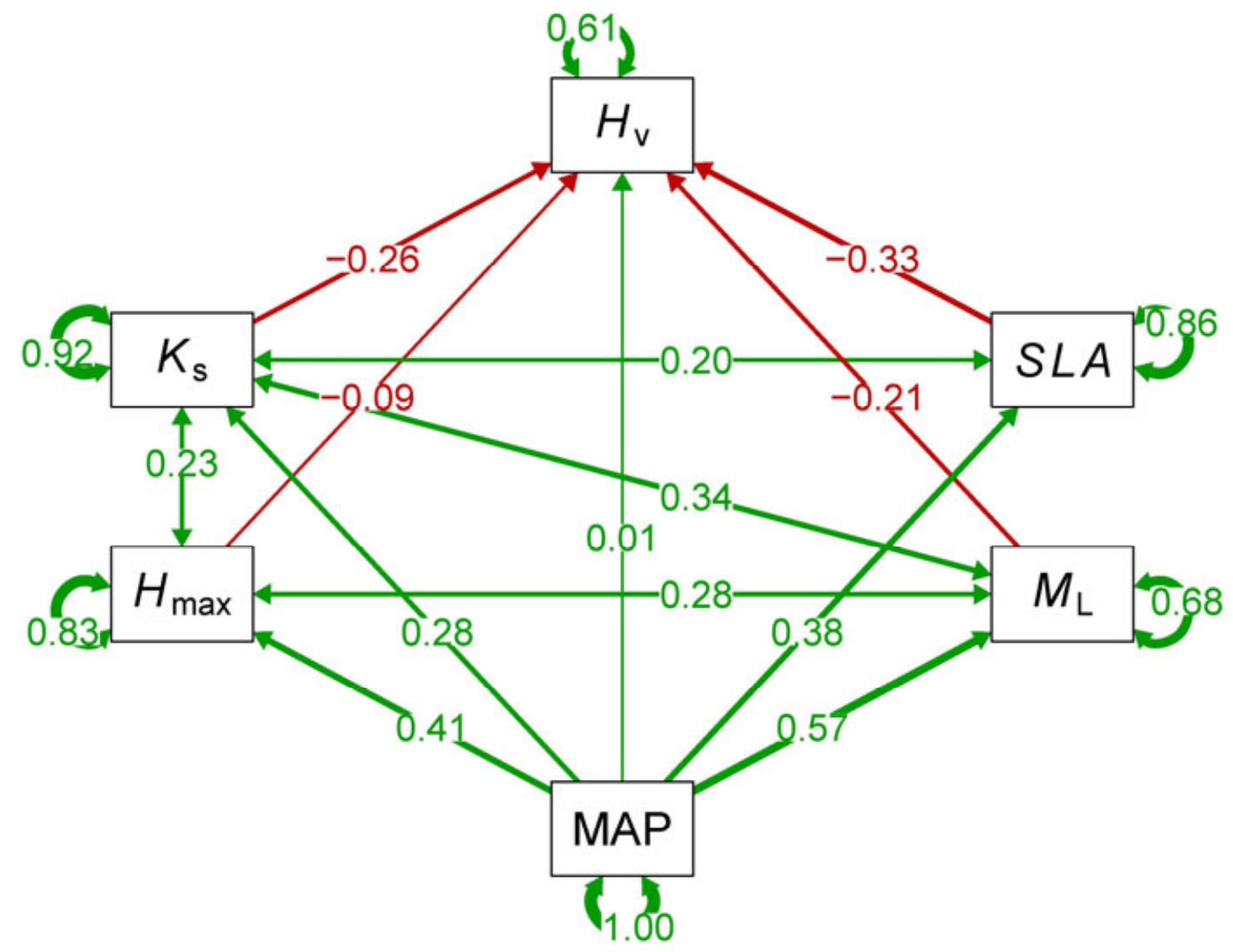

This article is protected by copyright. All rights reserved. 


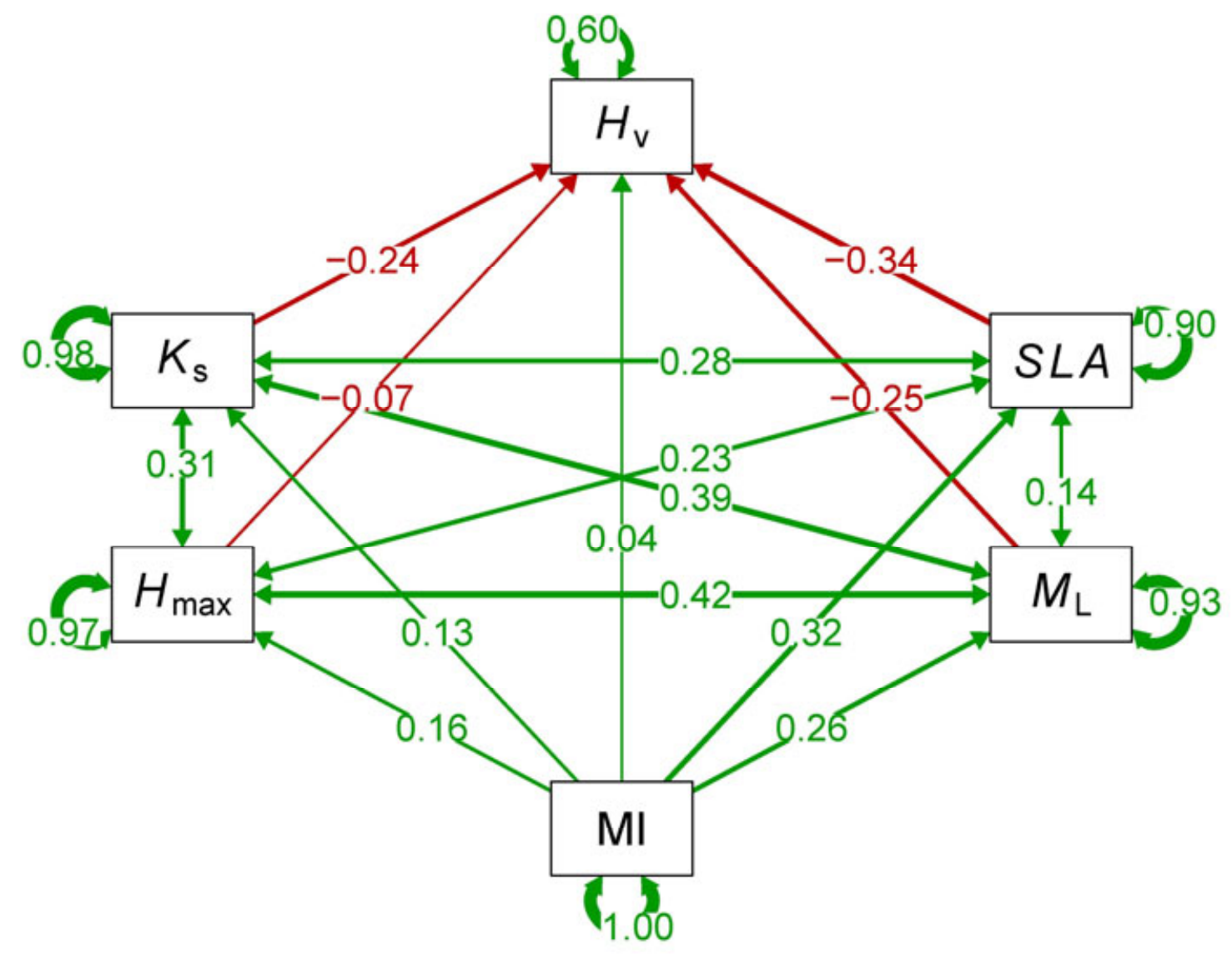

This article is protected by copyright. All rights reserved. 


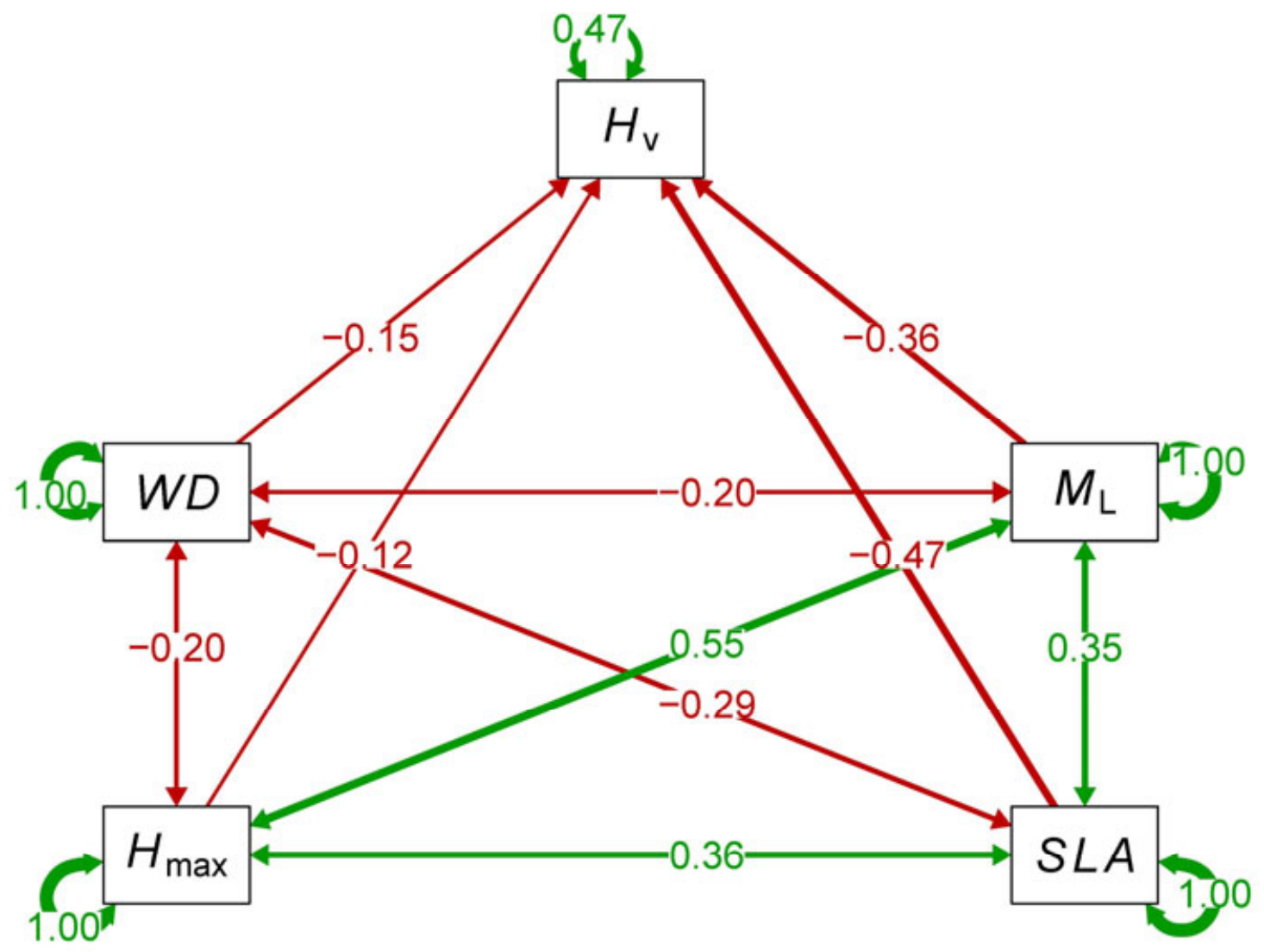

This article is protected by copyright. All rights reserved. 